\title{
Neurogenesis Continues in the Third Trimester of Pregnancy and Is Suppressed by Premature Birth
}

\author{
Sabrina Malik, ${ }^{1}$ Govindaiah Vinukonda, ${ }^{1}$ Linnea R. Vose, ${ }^{1}$ Daniel Diamond, ${ }^{1}$ Bala B. R. Bhimavarapu, ${ }^{2}$ Furong Hu, ${ }^{1}$ \\ Muhammad T. Zia, ${ }^{1}$ Robert Hevner, ${ }^{3}$ Nada Zecevic, ${ }^{4}$ and Praveen Ballabh ${ }^{1,2}$ \\ Departments of ${ }^{1}$ Pediatrics and ${ }^{2}$ Cell Biology and Anatomy, Regional Neonatal Center, Maria Fareri Children's Hospital at Westchester Medical Center and \\ New York Medical College, Valhalla, New York 10595, ${ }^{3}$ Department of Neurological Surgery, University of Washington, Seattle, Washington 98101, and \\ ${ }^{4}$ Department of Neuroscience, University of Connecticut Health Center, Farmington, Connecticut 06030
}

Premature infants exhibit neurodevelopmental delay and reduced growth of the cerebral cortex. However, the underlying mechanisms have remained elusive. Therefore, we hypothesized that neurogenesis in the ventricular and subventricular zones of the cerebral cortex would continue in the third trimester of pregnancy and that preterm birth would suppress neurogenesis. To test our hypotheses, we evaluated autopsy materials from human fetuses and preterm infants of 16-35 gestational weeks (gw). We noted that both cycling and noncycling Sox $2{ }^{+}$radial glial cells and Tbr $2^{+}$intermediate progenitors were abundant in human preterm infants until 28 gw. However, their densities consistently decreased from 16 through 28 gw. To determine the effect of premature birth on neurogenesis, we used a rabbit model and compared preterm [embryonic day 29 (E29), $3 \mathrm{~d}$ old] and term (E32, <2 h old) pups at an equivalent postconceptional age. Glutamatergic neurogenesis was suppressed in preterm rabbits, as indicated by the reduced number of Tbr $2^{+}$intermediate progenitors and the increased number of Sox ${ }^{+}$radial glia. Additionally, hypoxia-inducible factor-1 $\alpha$, vascular endothelial growth factor, and erythropoietin were higher in term than preterm pups, reflecting the hypoxic intrauterine environment of just-born term pups. Proneural genes, including Pax6 and Neurogenin-1 and -2, were higher in preterm rabbit pups compared with term pups. Importantly, neurogenesis and associated factors were restored in preterm pups by treatment with dimethyloxallyl glycine, a hypoxia mimetic agent. Hence, glutamatergic neurogenesis continues in the premature infants, preterm birth suppresses neurogenesis, and hypoxia-mimetic agents might restore neurogenesis, enhance cortical growth, and improve neurodevelopmental outcome of premature infants.

\section{Introduction}

The human cerebral cortex is complex and highly organized, which distinguishes humans from other species. The cerebral cortex orchestrates cognitive functions, intelligence, motor abilities, and sensory perceptions. Unraveling its development after midpregnancy might elucidate the mechanisms of its expansion and enhance the understanding of neurological disorders in premature infants. Therefore, we asked whether neurogenesis continues in prematurely born infants.

Every year, about 15 million infants are born preterm worldwide. These infants exhibit significant reduction in cortical gray matter volume and manifest with moderate to severe neurodevelopmental disability at 1 year of age (Dyet et al., 2006; Thompson et al., 2007). They continue to display impaired cortical growth even in childhood and adolescence (de Kieviet et al.,

Received Sept. 17, 2012; revised 0ct. 9, 2012; accepted 0ct. 14, 2012.

Author contributions: P.B. designed research; S.M., G.V., L.R.V., D.D., B.B.R.B., F.H., M.T.Z., and P.B. performed research; R.H. contributed unpublished reagents/analytic tools; P.B. analyzed data; L.R.V., N.Z., and P.B. wrote the paper.

This work was supported by NIH-NINDS Grant R01 NS071263 (P.B.), a scientist development grant from the American Heart Association (G.V.), and a Marshall Klaus grant from the American Academy of Pediatrics (S.M.). We thank Joanne Abrahams for the assistance with images.

Correspondence should be addressed to Dr. Praveen Ballabh, Regional Neonatal Center, Maria Fareri Children's Hospital at Westchester Medical Center, Valhalla, NY 10595. E-mail: Pballabh@msn.com.

DOI:10.1523/JNEUROSCI.4445-12.2013

Copyright $\odot 2013$ the authors $\quad 0270-6474 / 13 / 330411-13 \$ 15.00 / 0$
2012). Premature infants frequently develop complications, including intraventricular hemorrhage, hypoxia, ischemia, and sepsis, which reduce cortical growth and development (Vasileiadis et al., 2004). These neonatal disorders may impact neurogenesis, causing an imbalance between excitatory glutamatergic and inhibitory GABAergic neurons. The imbalance of excitation and inhibition within neural microcircuitry is associated with epilepsy, autism, neurodevelopmental disorders, and psychiatric illnesses, which are more common in preterm than term infants (Whitaker et al., 1997; Indredavik et al., 2010). Hence, it is important to determine how developmental neurogenesis progresses during the third trimester of pregnancy when premature infants are born.

In primates, glutamatergic neurogenesis occurs in the ventricular zone (VZ) and subventricular zone (SVZ) of the dorsal telencephalon, whereas GABAergic neurogenesis takes place in both ventral (ganglionic eminence) and dorsal telencephalon (Letinic et al., 2002; Jakovcevski et al., 2011). Cortical projection neurons, which are primarily glutamatergic, originate from radial glia residing in the dorsal VZ and SVZ. Radial glial cells in the VZ generate intermediate progenitor cells (IPCs) that migrate to the SVZ to further divide, migrate, and form the six cortical layers (Haubensak et al., 2004). During infancy, migrating immature neurons have been found to be abundant in the SVZ and rostral migratory system (Sanai et al., 2011). Neurogenesis has been studied in $<24$ gestational weeks (gw) and in term infants (Han- 
sen et al., 2010; Wang et al., 2011), but not in preterm infants (24-35 gw).

Neurogenesis is temporally regulated, and premature birth might affect it. Oxygen is a key regulator of neurogenesis (Panchision, 2009). Oxygen concentration in cerebral circulation is 25-30 $\mathrm{mmHg}$ in fetuses (in utero), which increases to 50-60 mmHg shortly after premature birth (Soothill et al., 1986). Increasing evidence indicates that hypoxia enhances proliferation of neuronal progenitors in vitro (Horie et al., 2004). Thus, a withdrawal of physiological hypoxia with premature birth might suppress neuronal differentiation (Horie et al., 2008). Hypoxia activates hypoxia-inducible factor (HIF)- $1 \alpha$, which regulates erythropoietin (EPO), vascular endothelial growth factor (VEGF), WNT/ $\beta$-catenin activity, and several signaling pathways (Zheng et al., 2008). These factors exert direct effects on neurogenesis. Therefore, we hypothesized that neurogenesis in the VZ and SVZ of the cerebral cortex would continue in the third trimester of pregnancy and that preterm birth might suppress neurogenesis. We also postulated that the HIF- $1 \alpha$ activation would restore neurogenesis in premature infants.

\section{Materials and Methods}

Human subjects. The Institutional Review Board at New York Medical College and Westchester Medical Center (Valhalla, NY) approved the use of autopsy materials from fetuses and premature infants for this study. The study materials included brain tissues sampled from spontaneous abortuses of 16-22 gw and autopsies of premature infants of 23-40 gw. The autopsy samples were obtained at a postmortem interval of $<18 \mathrm{~h}$ for premature infants and $<8 \mathrm{~h}$ for fetuses. Only infants of $<5 \mathrm{~d}$ postnatal age were included in the study to minimize the effect of postnatal events on neurogenesis occurring in the neonatal intensive care units. We excluded premature infants with grade 2-4 intraventricular hemorrhage, major congenital anomalies, chromosomal defects, culture-proven sepsis, meningitis, hypoxic-ischemic encephalopathy, and infants receiving extracorporeal membrane oxygenator treatment from the study. Any brain tissue showing autolysis or necrosis on hematoxylin and eosin staining was also excluded. Autopsy samples were classified into five groups: (1) fetuses of 16-19 gw ( $n=5),(2)$ fetuses of $20-22 \mathrm{gw}(n=5)$, (3) premature infants of $23-25 \mathrm{gw}(n=5)$, (4) premature infants of $26-28 \mathrm{gw}(n=5)$, and (5) premature infants of $29-35 \mathrm{gw}(n=5)$. Of these, 10 were females and 15 were males. These samples were collected over the last 10 years (2002-2012) at New York Medical CollegeWestchester Medical Center (Valhalla, NY).

Human tissue collection and processing. Brain samples were processed as described previously (Ballabh et al., 2007). Coronal blocks (5-6 mm) were cut through frontal cortex (cortical plate), white matter (embryonic intermediate layer), and germinal matrix in the region of the thalamostriate groove at the level of interventricular foramen (Monro's foramen). The samples were fixed in $4 \%$ paraformaldehyde in PBS (0.01 M, pH 7.4) for $18 \mathrm{~h}$ and cryoprotected by immersing into $20 \%$ sucrose in PBS buffer for $24 \mathrm{~h}$, followed by $30 \%$ sucrose for the next $24 \mathrm{~h}$. We froze tissues after embedding them into optimum cutting temperature compound (Sakura), and blocks were stored at $-80^{\circ} \mathrm{C}$. Frozen coronal blocks were cut into $12 \mu \mathrm{m}$ sections using a cryostat and saved at $-80^{\circ} \mathrm{C}$ until use.

Animal experiments. The Institutional Animal Care and Use Committee of New York Medical College approved the use of animals for the study. We obtained timed-pregnant New Zealand rabbits from Charles River Laboratories. C-section was performed to deliver the pups prematurely at embryonic day 29 (E29; full term is $32 \mathrm{~d}$ ). We kept the pups in an infant incubator prewarmed to a temperature of $35^{\circ} \mathrm{C}$. The pups were fed $2-3 \mathrm{ml}(100 \mathrm{ml} / \mathrm{kg}$ ) of puppy formula (Esbilac) twice daily in the first $2 \mathrm{~d}$, and subsequently the feed was advanced to $125,150,200,250$, and 280 $\mathrm{ml} / \mathrm{kg}$ at postnatal days $3,5,7,10$, and 14 , respectively. We also included full-term (E32) rabbit pups in the study delivered by two pregnant rabbits. Live born and healthy looking pups of either sex were included in the study. Pups with postnatal complications including aspiration of for-
Table 1. Characteristics of human fetuses and premature infants studied

\begin{tabular}{rllll}
\hline & Gestational & & & \\
Case & age (weeks) & Weight $(\mathrm{g})$ & Sex & Clinical diagnosis and cause of death \\
\hline 1 & 16 & & Male & Cervical incompetence \\
2 & 17 & & Male & Undetermined \\
3 & 17 & & Female & Placental abruption \\
4 & 19 & & Male & Undetermined \\
5 & 19 & 240 & Female & Cervical incompetence \\
6 & 20 & 360 & Female & Multiple pregnancy \\
7 & 20 & 320 & Male & Preterm labor \\
8 & 21 & 410 & Female & Preterm labor \\
9 & 21 & 460 & Male & Preterm labor \\
10 & 22 & 510 & Male & Preterm labor \\
11 & 23 & 400 & Female & Immaturity and respiratory failure \\
12 & 23 & 630 & Male & Immaturity and respiratory failure \\
13 & 24 & 390 & Male & Immaturity and respiratory failure \\
14 & 25 & 740 & Male & Clinical sepsis \\
15 & 25 & 730 & Female & Metabolic acidosis, cardiorespiratory failure \\
16 & 26 & 920 & Female & Clinical sepsis and shock \\
17 & 27 & 550 & Female twin & Respiratory failure \\
18 & 27 & 925 & Male & Respiratory failure \\
19 & 27 & 480 & Male & Clinical sepsis \\
20 & 28 & 900 & Male & Respiratory failure \\
21 & 31 & 3390 & Male & Hydrops fetalis \\
22 & 32 & 992 & Male & Necrotizing enterocolites \\
23 & 33 & 3380 & Male & Nonimmune hydrops \\
24 & 33 & 2305 & Female & Diaphragmatic hernia \\
25 & 35 & 2900 & Female & Oligohydramnios, hypoplastic lung \\
\hline & & & &
\end{tabular}

mula, cardiac arrest requiring resuscitation, and any apparent congenital defect were excluded from the study.

Dimethyloxallyl glycine treatment. To stabilize HIF- $1 \alpha$, we treated E29 rabbit pups with dimethyloxallyl glycine (DMOG; Cayman Chemical) starting immediately at birth. DMOG was administered in a dose of 100 $\mathrm{mg} / \mathrm{kg}$ daily intramuscular for $3 \mathrm{~d}$. These pups were killed at $72 \mathrm{~h}$ of age. The comparison group received vehicle ( $15 \mu \mathrm{l}$ of DMSO).

Rabbit tissue collection and processing. We processed the tissues as described previously (Dummula et al., 2010). Two- to three-micrometerthick coronal slices, taken at the level of midseptal nucleus of the forebrain, were immersion fixed in $4 \%$ paraformaldehyde in PBS $(0.01 \mathrm{M}$, $\mathrm{pH}$ 7.4) for $18 \mathrm{~h}$. Samples were then cryoprotected by immersing into $20 \%$ sucrose in 0.01 м PBS for $24 \mathrm{~h}$, followed by $30 \%$ sucrose for the next $24 \mathrm{~h}$. Tissues were frozen into optimum cutting temperature compound. Frozen coronal blocks were cut on a cryostat into $30 \mu \mathrm{m}$ sections.

Immunohistochemistry. Immunostaining was performed as described previously (Ballabh et al., 2007). The primary antibodies used in experiments included goat polyclonal SOX-2 (catalog \#SC-6895; Santa Cruz Biotechnology), rabbit polyclonal TBR2 (courtesy of R.H.), rabbit monoclonal Ki67 (catalog \#275R-14; Cell Marque), mouse monoclonal Ki67 (catalog \#M7240; Dako), mouse monoclonal phospho-vimentin (catalog \#D076-3; MBL International), mouse monoclonal GFAP (catalog \#G3893; Sigma-Aldrich), and mouse monoclonal vimentin (catalog \#V6630; Sigma-Aldrich). The secondary antibodies used were Alexa 488 donkey anti-mouse, Alexa 647 donkey anti-goat, and Alexa 594 donkey anti-rabbit (Invitrogen). Briefly, we hydrated the fixed sections in $0.01 \mathrm{M}$ $\mathrm{PBS}$ and incubated them with the primary antibodies diluted in PBS at $4^{\circ} \mathrm{C}$ overnight. After washing in PBS, the sections were incubated with a secondary antibody diluted in 1\% normal donkey serum in PBS at room temperature for $60 \mathrm{~min}$. Finally, after washes in PBS, sections were mounted with Slow Fade Light Antifade reagent (Invitrogen) and were visualized under a confocal microscope (Nikon). Stereology was performed using a fluorescent microscope (Axioskop 2 plus; Carl Zeiss) with a motorized specimen stage for automated sampling (ASI), CCD color video camera (Microfire; Optronics), and stereology software (Stereologer; SRC).

Quantification of neuronal progenitors under confocal microscope. We quantified Sox2- and Tbr2-positive cells and their proliferation in five groups of subjects: $16-19,20-22,23-25,26-28$, and $29-35$ gw $(n=5$ 

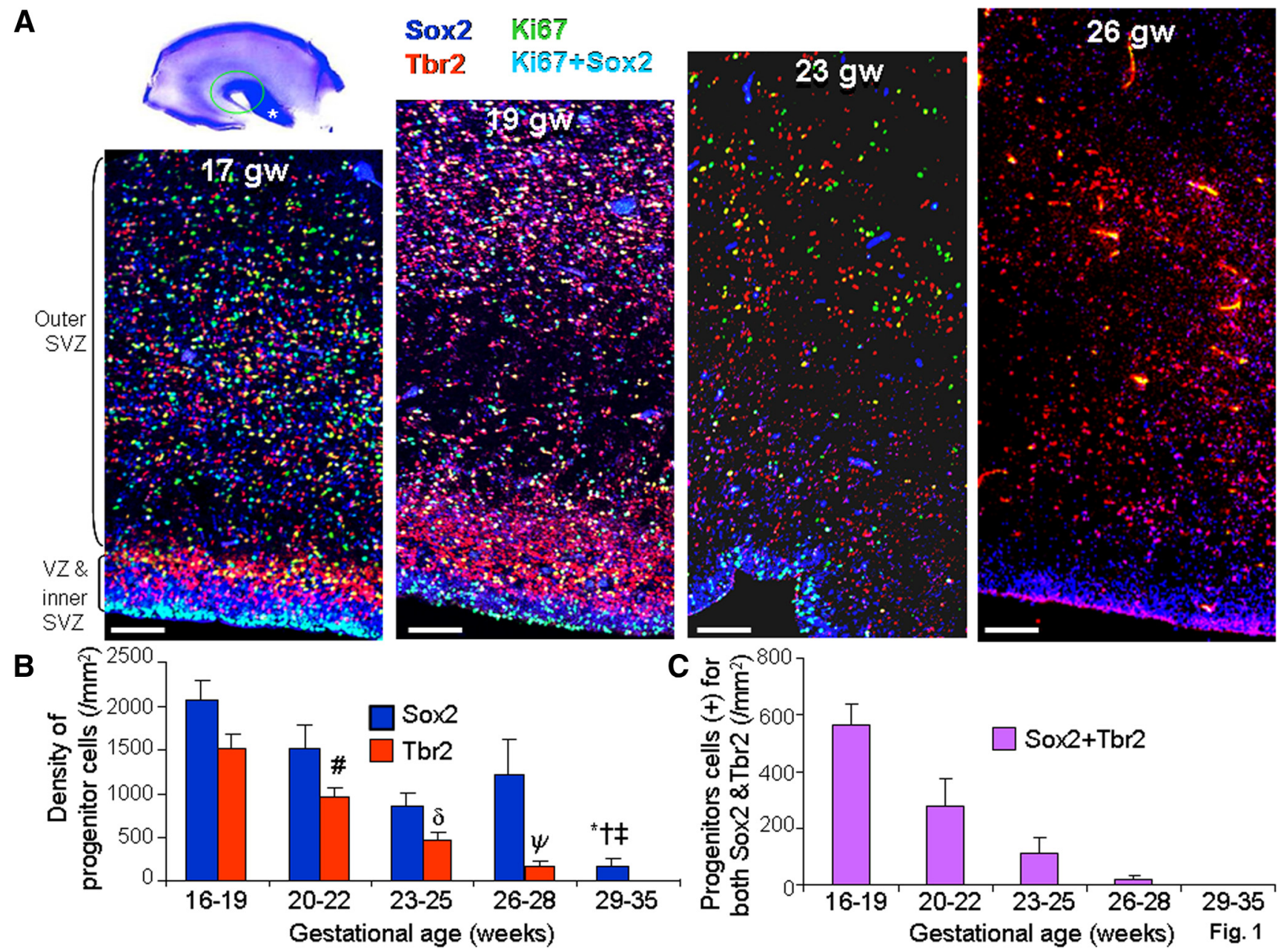

Figure 1. Neurogenesis continues in dorsal SVZ until $28 \mathrm{gw}$. A, Representative immunofluorescence of cryosections from subjects of 17, 19, 23, and 26 gw triple labeled with Sox2, Tbr2, and Ki67 antibodies. There was an abundance of Sox ${ }^{+}$and Tbr2 ${ }^{+}$neuronal progenitors in the VZ and SVZ that decrease in density with increasing gestational age. A cresyl violet-stained coronal section from $17 \mathrm{gw}$ forebrain (top left) shows dorsal cortical SVZ (green circle) and ganglionic eminence (asterisk); all images were acquired in dorsal SVZ. Scale bars, $100 \mu \mathrm{m}$. $\boldsymbol{B}$, Densities of Sox2 ${ }^{+}$and $\mathrm{Tbr}^{+}$cells progressively reduce with advancing gestational age, becoming scarce after $28 \mathrm{gw}$. Bar charts are mean \pm SEM. ${ }^{*} p<0.001,{ }^{\dagger} p=0.026$, and ${ }^{\ddagger} p=0.047$ for the comparison of Sox $2^{+}$ cells between $29-35$ gw versus $16-19,20-22$, and $26-28 \mathrm{gw}$, respectively. ${ }^{*} p<0.001$ and ${ }^{\delta} p<0.001$ each for the comparison of Tbr2 ${ }^{+}$cells between $16-19$ versus $20-22$ gw and $20-22$ versus $23-25$ gw. ${ }^{*} p<0.03$ for the comparison of Tbr ${ }^{+}$cells between $23-25$ versus $26-28$ gw. C, Bar charts are mean \pm SEM. Neuronal progenitors coexpressing Sox 2 and Tbr 2 significantly decline in density with increasing gestational age, disappearing by $28 \mathrm{gw}$.

each group, 25 subjects total). From each brain, four to six coronal sections were obtained. Coronal brain sections were triple labeled with Sox2-, Tbr2-, and Ki67-specific antibodies to evaluate density and proliferation of Sox $2^{+}$and Tbr2 ${ }^{+}$cells. To determine the proportion of Sox ${ }^{+}$and $\mathrm{Tbr}^{+}$cells compared with all neural cells, we labeled another set of coronal sections with Sox2, Tbr2, and Sytox (nuclear stain). The counting was done in six representative images from each brain region (dorsal cortical SVZ and ganglionic eminence) acquired on a confocal microscope (Nikon) using $60 \times$ objective. Of these, three images were taken at the level of the ventricular surface encompassing the VZ and inner SVZ, and the remaining three images were acquired above the initial ones (outer SVZ). All counting was done on the confocal microscope (EZ-C1 program) by using the "point of interest" icon from menu bar. Hence, we counted objects in approximately six images per brain region (ganglionic eminence and dorsal SVZ) of each brain section (6 images $\times 2$ brain regions $\times 4-6$ sections $\times 25$ brains). Stereological protocol was not followed for the quantification of cells in human brains because triple-labeled live images cannot be obtained by a regular fluorescent microscope equipped with stereology software. Hence, the counting was done on a confocal microscope by an investigator blinded to the experimental group.

We also quantified doublecortin (DCX)-labeled cells in four groups of human subjects: $16-22,23-25,26-28$, and 29-35 gw $(n=4$ each group,
16 subjects total). To this end, we triple labeled forebrain coronal sections with DCX, Ki67, and Sytox. The counting was done in dorsal cortical SVZ and ganglionic eminence, just as for Sox2 and Tbr2, by a blinded investigator on the confocal microscope.

Stereological assessment of Sox2-, Tbr2-, and Ki67-positive cells in rabbits. Unbiased stereology methods, with assistance from a computerized software system (Stereologer; Stereology Resource Center), were used to quantify a range of parameters in two brain regions: (1) dorsal VZ and SVZ underneath the corona radiata and corpus callosum and (2) lateral ganglionic eminence (forms the lateral margin of the cerebral ventricles). Briefly, coronal sections were cut on a cryostat at a setting of $30 \mu \mathrm{m}$ thickness with a section sampling interval of three $(90 \mu \mathrm{m})$ to achieve at least six sections at the level of midseptal nucleus. The sections were triple labeled with Sox 2 or Tbr2 with Ki67 antibodies and DAPI (nuclear stain) and quantified as follows. The reference spaces (dorsal VZ and SVZ) were first outlined on the section under $5 \times$ objective. The volume of the outlined area (reference space) was quantified using a point counting probe (frame, $25 \times 25 \mu \mathrm{m}$; guard zone, $2 \mu \mathrm{m}$; interframe interval, 300 $\mu \mathrm{m})$. The total number of Sox $2^{+}$, Tbr $2^{+}$, or $\mathrm{Ki} 67^{+}$cells labeled with their respective antibodies through a defined reference space was quantified using the optical dissector probe under a $60 \times$ oil lens. For the optical dissector probe (frame, $25 \times 25 \mu \mathrm{m}$; guard zone, $1 \mu \mathrm{m}$; interframe interval, $200 \mu \mathrm{m})$, the user clicked on the objects within the dis- 
sector frame. Sampling continued until the coefficient of error was $<0.10$. To assess cells positive for both Ki67 and Sox2, we used a dual-color filter (filter set $74 \mathrm{HE} \mathrm{GFP}+\mathrm{mRFP}$ shift free; Zeiss) that visualizes both Alexa 488and Alexa 594-labeled cells.

Western blot analyses. We homogenized the frozen brain tissue in sample buffer (3\% SDS, $10 \%$ glycerol, $62.5 \mathrm{~mm}$ Tris- $\mathrm{HCl}$, and $100 \mathrm{~mm}$ DL-DTT) using a mechanical homogenizer and boiled the samples immediately for $5 \mathrm{~min}$. The protein concentration in the supernatant was determined using the BCA Protein Assay kit (Pierce catalog \#23227). Total protein samples were separated by SDS-PAGE according to the previously described method (Ballabh et al., 2007). Equal amounts of protein $(10-20 \mu \mathrm{g})$ were loaded into a $4-15 \%$ gradient precast gel (Bio-Rad). The separated proteins were transferred onto polyvinylidene difluoride membrane by electro-transfer. The membranes were then incubated with primary antibodies [mouse monoclonal HIF- $1 \alpha$ (catalog \#SC53546) and mouse monoclonal VEGF (catalog \#SC-7269), Santa Cruz Biotechnology; rabbit polyclonal Pax6, catalog \#PRB-278P, Covance]. We detected target proteins with a chemiluminescence ECL system (GE Healthcare) by using secondary antibodies conjugated with horseradish peroxidase (Jackson ImmunoResearch Laboratories). We next stripped the blots with stripping buffer (Pierce) and incubated with $\beta$-actin primary antibody, followed by a secondary antibody and detection with the chemiluminescence ECL system. As described previously (Ballabh et al., 2007), the blots from each experiment were densitometrically analyzed using ImageJ. The optical density values were normalized by taking the ratio of the target protein and $\beta$-actin.

Quantitative real-time PCR. Quantitative realtime PCR (qRT-PCR) was performed as described previously (Ballabh et al., 2007). Briefly, total RNA was isolated from a 1- to 2-mm-thick slice taken at the level of midseptal nucleus of the forebrain by the Mini RNA isolation kit (Zymo Research). RNA was reverse-transcribed using Superscript II RT (Invitrogen). Real-time reverse transcriptase-PCR was used to analyze mRNA expression using an ABI PRISM 7700 Sequence Detection System (Applied Biosystems). Quantification was performed using the efficiencycorrected $\Delta \Delta \mathrm{CT}$ method. The following primers were used for qRT-PCR: Pax6 (accession number NM_001082217.1) sense CCCGTCCATCTTTG CTTGGGAAAT, antisense TAGCCAGGTTGC GAAGAACTCTGT; Neurogenin-2 (accession numberXM_002717014.1) sense GCATCAAGA AGACACGCAGACTGA, antisense TCTCGATC TTGGTTAGCTTGGCGT; Neurogenin-1 (accession number XM_002710221.1) sense AACCGCATGCACAACCTG AA, antisense AAGCGTAGCGTCTCGATCTT; Hes1 (accession number XM_002716517.1) sense GAGCACAGGAAGTCTTCAAAGCCA, antisense TGGAATGCCGCGAGCTATCTTTCT; Hes5 (accession number NM_001010926.3) senseGCATCAACAGCAGCATCGAGCA, antisense TA GCTGACAGCCATCTCCAGGAT; Emx1 (accession number BC037242.1) sense TCCAGAACCGGAGGACAAAGTACA, antisense TGATGTGATG GGAGCCCTTCTTCT; Emx2 (accession number AF301598.1) sense AAGC
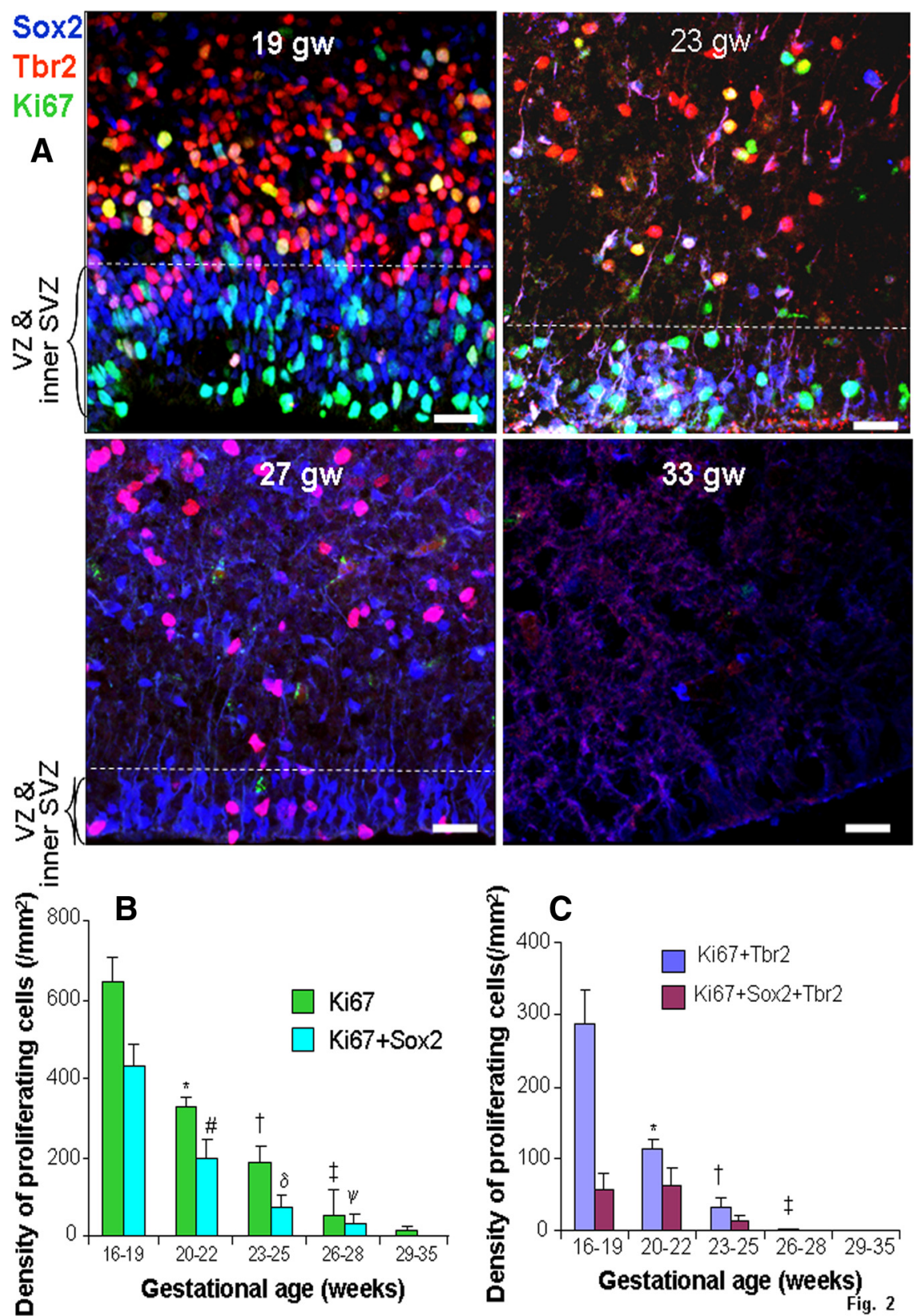

Figure 2. Proliferation of apical and basal progenitors reduce with advancing gestation. $A$, Typical morphology of radial glia $\left(S_{0 \times 2}{ }^{+}\right)$and IPCs $\left(\mathrm{Tbr}^{+}{ }^{+}\right)$in the VZ and SVZ of cryosections taken from 19, 23, 27, and 33 gw subjects triple labeled with Sox2, Tbr2, and Ki67 antibodies. The number of cycling and noncycling Sox2 ${ }^{+}$and Tbr2 ${ }^{+}$cells reduces with increasing gestation, becoming completely absent by $33 \mathrm{gw}$. Scale bars, $25 \mu \mathrm{m}$. The dashed lines indicate the intersection of inner and outer SVZ. $\boldsymbol{B}$, Densities of all proliferating cells and cycling Sox $2^{+}$cells decreased with advancing gestational age. Bar charts are mean \pm SEM. ${ }^{*} p<0.001,{ }^{\dagger} p<0.001$, and ${ }^{\ddagger} p<0.001$ for the comparison of all proliferating cells (Ki67 ${ }^{+}$) for $16-19$ versus $20-22 \mathrm{gw}, 16-19$ versus $23-25$ gw and $20-22$ versus $26-28$ gw, respectively. ${ }^{\#} p<0.001$ and ${ }^{\delta} p<0.001$ for Sox2 ${ }^{+}$cells comparing $16-19$ versus $20-22$ gw and $16-19$ versus $23-25 \mathrm{gw}$, respectively. ${ }^{*} p=0.024$ for Sox ${ }^{+}$cells comparing $20-22$ versus $26-28 \mathrm{gw}$, respectively. C, Densities of cycling cells labeled Tbr2 and colabeled Sox2 ${ }^{+}$and Tbr2 ${ }^{+}$decreased with rising gestational age. Bar charts are mean \pm SEM. ${ }^{*} p<0.001$ and ${ }^{\dagger} p<0.001$ for the comparison of proliferating Tbr ${ }^{+}$cells for both $16-19$ versus $20-22$ gw and $16-19$ versus $23-25 \mathrm{gw}, p<0.001 .{ }^{\ddagger} p=0.008$ for the comparison of cycling Tbr ${ }^{+}$cells at $20-22$ versus $26-28 \mathrm{gw}$.

GCTGCTTCACCATCGAGT,antisenseAGCCGTTGAGGAACGGATTT ATGG; Insulinoma associated 1 (Insm 1 ; accession number NM_002196.2) sense ACTTCGAGGACGAGGTGACCA, antisense TT GCACAGCTGGCAGATGAACT; VEGF (accession number NM_003376) sense AGACGGACAGAAAGACAG, antisense AAGCAGGTGAGAGTAAGC.

Statistics and analysis. Data are expressed as means \pm SEM. To determine differences in the density of radial glia and IPCs and their prolifer- 

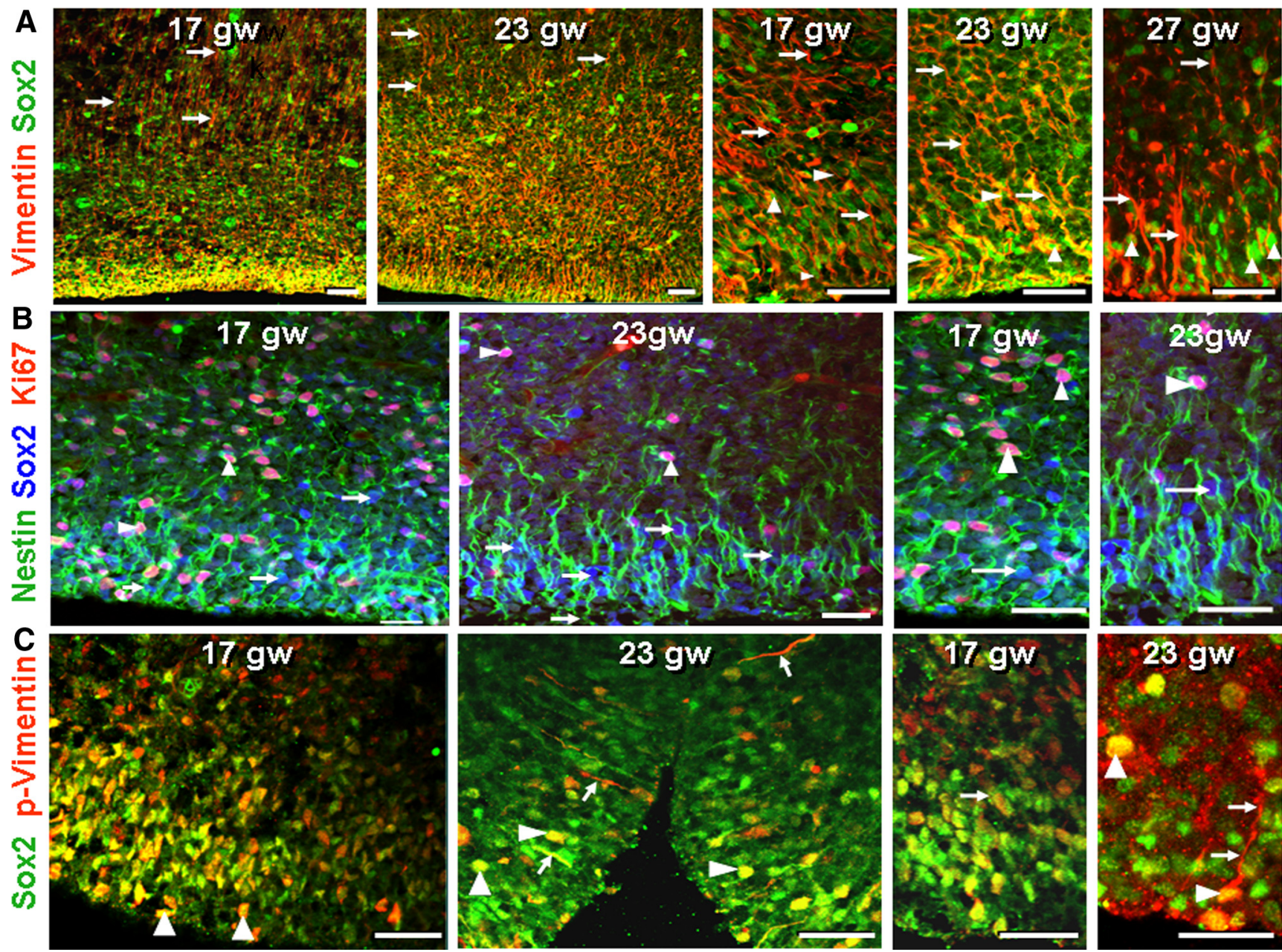

Figure 3. Sox $2+$ radial glial cells show apical and basal processes in fetuses and premature infants. A, Double immunolabeling at 17, 23 , and $27 \mathrm{gw}$ with Sox 2 and vimentin antibodies. Note the basal radial glial processes in outer SVZ (arrow) and predominance of Sox2 ${ }^{+}$cells (arrowhead) in VZ and inner SVZ. Sox2 ${ }^{+}$cells were embedded into vimentin. Scale bars, $25 \mu \mathrm{m} . \boldsymbol{B}^{\text {, Triple }}$ immunolabeling of cryosections from 17 and 23 gw subjects with Sox2, nestin, and Ki67 antibodies. Nestin-positive radial glial processes surround the Sox2-positive (arrow) and Ki67-positive (arrowhead) nuclear signals. Scale bars, $25 \mu \mathrm{m}$. C, In 17 and $23 \mathrm{gw}$ subjects, double labeling with Sox2 and p-vimentin antibodies shows colocalization of two immunoreactivities at several locations (arrowheads), indicating that the radial glial cells are in M phase. Note the processes of p-vimentin ${ }^{+}$cells extending into SVZ (arrows). Scale bars, $25 \mu \mathrm{m}$.

ation in the dorsal SVZ and ganglionic eminence in five age groups of human subjects (including 16-19, 20-22, 23-25, 26-28, and 29-35 gw), two-way ANOVA with repeated measures was used. The repeated factor was applied to the two brain regions, dorsal SVZ and ganglionic eminence. To compare the density of radial glia and IPCs and their proliferation in treated preterm, untreated preterm, and term rabbit pups, we used one-way ANOVA. For Western blot analyses, three group comparisons were done using one-way ANOVA. All post hoc comparisons to test for differences between means were done using Tukey's multiple comparison test at the 0.05 significance level. For two group comparisons, either the $t$ test or Mann-Whitney $U$ test was performed, as applicable.

\section{Results}

Radial glia and intermediate progenitors populate dorsal SVZ of premature infants

To evaluate neurogenesis, radial glia (apical progenitors) and IPCs (basal progenitors) were assessed in the dorsal SVZ and VZ of five subgroups of human fetuses and premature infants: $16-$ $19,20-22,23-25,26-28$, and $29-35 \mathrm{gw}(n=5$ in each group; Table 1). We identified radial glia and IPCs by immunolabeling with antibodies for Sox 2 and T-brain gene 2 (Tbr2) transcription factors, respectively. Ki67, which labels cells in late $G_{1}, S, G_{2}$, and $\mathrm{M}$ phases of the cell cycle, was chosen to assess proliferation of radial glia and IPCs. Immunostaining of coronal sections re- vealed that Sox ${ }^{+}$cells were abundant in the VZ and SVZ of fetuses and premature infants (Figs. 1, 2). However, their densities decreased with advancing gestational age $(p<0.001$; Fig. $1 B$ ), becoming scarce to absent in preterm infants older than 28 gw. Comparison between the five groups showed that Sox $2{ }^{+}$cells were fewer in $29-35 \mathrm{gw}$ infants compared with $16-19,20-22$, and $26-28$ gw infants ( $p<0.001,0.026$, and 0.047 , respectively). To determine whether Sox $2^{+}$cells exhibited apical and basal processes, we double labeled the sections with Sox 2 and vimentin antibodies. Vimentin was expressed on basal and apical processes of the radial glia surrounding the Sox $2^{+}$nuclear labeling (Fig. $3 A)$. Many Sox $2^{+}$cells showed vimentin-positive apical processes; however, the basal processes could not be traced deep into the white matter. Similarly, nestin was expressed on radial glial processes encircling the Sox ${ }^{+}$nuclear labeling (Fig. 3B).

Similar to Sox $2^{+}$cells, $\mathrm{Tbr}^{+}{ }^{+}$IPCs were abundant in the SVZ of fetuses and premature infants ( $16-28$ gw; Figs. 1,2). A pairwise comparison between the five groups of subjects showed a progressive decline in the number of Tbr $2^{+}$cells with advancing gestational age ( $p<0.001$ for three comparisons: $16-19$ vs $20-22$ gw, $20-22$ vs $23-25$ gw, and $23-25$ vs $29-35$ gw; $p<0.03$ for $23-25$ vs $26-28$ gw; Fig. $1 B$ ). Notably, Tbr $2^{+}$cells were almost 
A
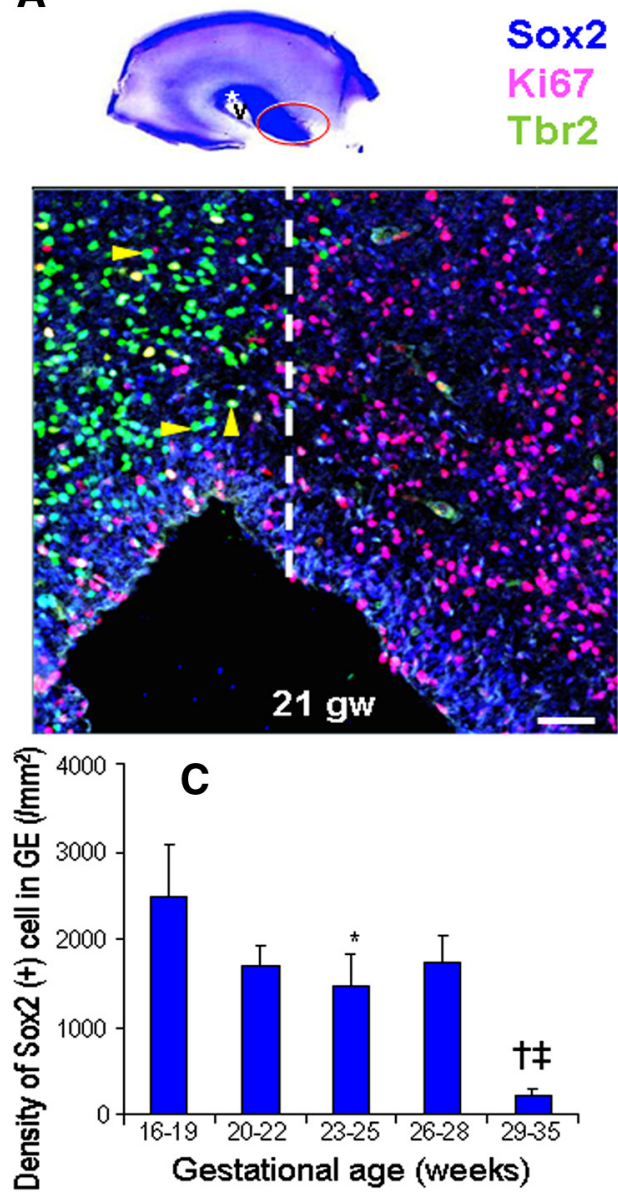

B
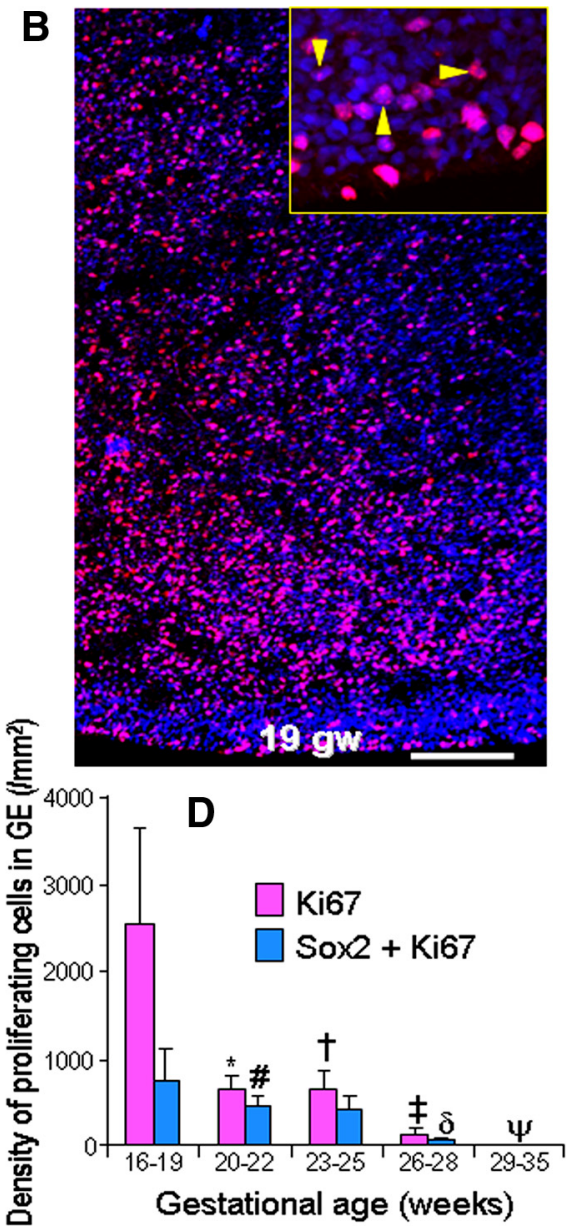
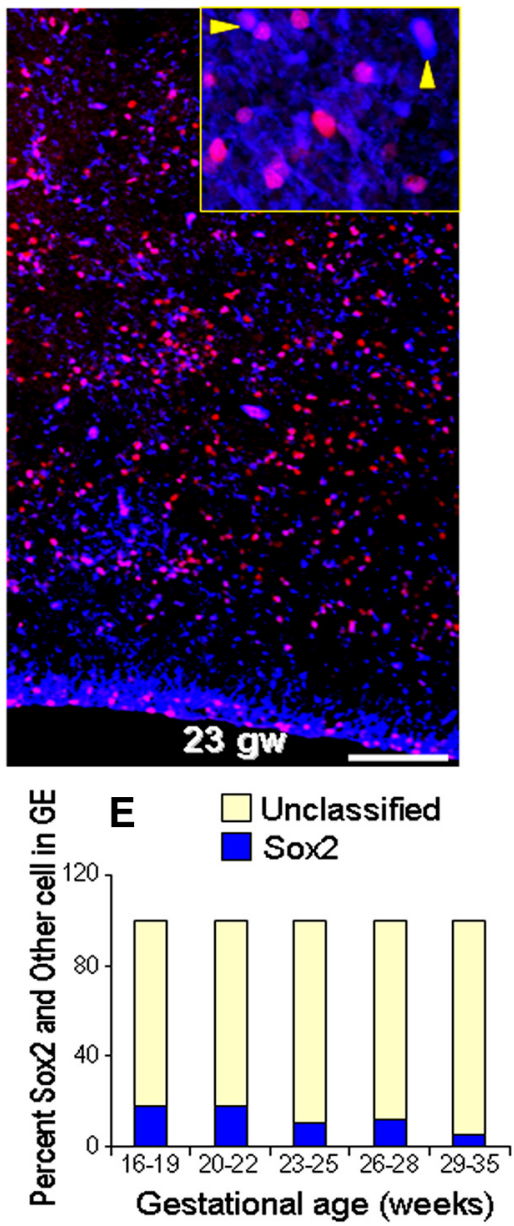

Figure 4. Neurogenesis in ganglionic eminence continues until $28 \mathrm{gw}$. $\boldsymbol{A}$, Representative immunofluorescence of cryosections from subjects of $21 \mathrm{gw}$, triple labeled with Sox2, Tbr2, and Ki67 antibodies. Note that Tbr2 ${ }^{+}$cells (arrowheads) are absent in the ganglionic eminence; the dashed line marks a sharp demarcation in the SVZ between dorsal (cortical) SVZ and ventrally located ganglionic eminence with respect to the distribution of Tbr2 ${ }^{+}$cells. Scale bar, $50 \mu \mathrm{m}$. Cresyl violet-stained coronal section from $17 \mathrm{gw}$ (top left) forebrain shows ganglionic eminence (red circle),

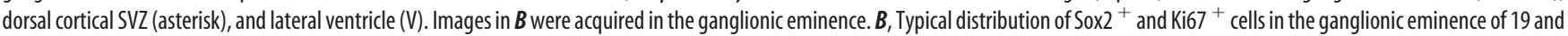

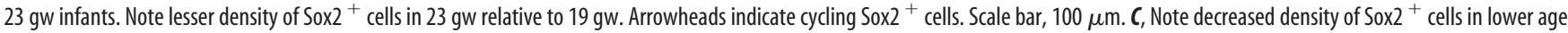
groups. Bar charts are mean \pm SEM. ${ }^{*} p<0.001$ for $16-19$ versus $23-25 \mathrm{gw} ;{ }^{\dagger} p=0.017$ for $20-22$ versus $29-35$ gw; ${ }^{\ddagger} p=0.013$ for $26-28$ versus $29-35$ gw. $\boldsymbol{D}$, All cycling neural cells and proliferating Sox ${ }^{+}$cells decreased in density with advancing gestational age. Bar charts are mean \pm SEM. The following applies for all cycling cells: ${ }^{*} p<0.007$ for $16-19$ versus $20-22$ gw; ${ }^{\dagger} p<$ 0.01 and ${ }^{\ddagger} p<0.01$ for $16-19$ versus $23-25$ and $26-28 \mathrm{gw}$, respectively. The following applies for proliferating Sox2 ${ }^{+}$cells: \#p $<0.001,{ }^{\delta} p<0.001$, and ${ }^{\psi} p<0.001$ for $16-19$ vs $20-22$, $26-28$, and $29-35 \mathrm{gw}$, respectively. $\boldsymbol{E}$, Proportional bar diagram showing reduction in the density of percentage of Sox ${ }^{+}$cells with advancing gestational age.

undetectable after $28 \mathrm{gw}$. A subset of neuronal progenitors coexpressed Sox 2 and Tbr2, suggesting persistence of Sox 2 antigen after the birth of Tbr ${ }^{+}$IPCs. These Sox 2 and Tbr 2 colabeled cells of the $\mathrm{VZ}$ and $\mathrm{SVZ}$ reduced in density with increasing gestational age ( $p<0.001$; Fig. $1 C)$, becoming extinct after $28 \mathrm{gw}$.

The fetuses of $<23$ gw usually do not survive and thus are considered nonviable (Seri and Evans, 2008). Therefore, we compared the density of radial glia and IPCs between fetuses of $<23$ gw (16-22 gw, nonviable) and premature infants of 23 gw or more (23-28 gw, viable). To this end, we combined two subsets of fetuses (16-19 and 20-22 gw) and two subsets of preterm infants (23-25 and 26-29 gw) and compared these two groups. We found that the density of Sox $2^{+}$, Tbr $2^{+}$, and both Sox2-/Tbr2positive cells was significantly less in preterm infants compared with fetuses ( $p<0.025,0.001$, and 0.001 , respectively). Together, these results indicate that neurogenesis slows down as gestational age advances toward the age of viability.

Radial glia and IPCs were more numerous in the inner SVZ compared with the outer SVZ in fetuses. Conversely, in preterm infants, $\mathrm{Tbr} 2^{+}$cells appeared to be more abundant in the outer SVZ than the inner SVZ. Therefore, we compared densities of Sox $2^{+}$and $\mathrm{Tbr} 2{ }^{+}$cells between the outer SVZ and the inner SVZ (including VZ) in two subsets of preterm infants, 23-25 and 26-28 gw. We found that Tbr ${ }^{+}$cells exhibited a trend toward higher density in the outer SVZ, whereas Sox ${ }^{+}$ cells displayed a trend for larger number in the inner SVZ. However, the comparisons were not statistically significant (data not shown). Together, the relative abundance of apical $\left(\right.$ Sox $2^{+}$) and basal $\left(\mathrm{Tbr} 2^{+}\right.$) neuronal progenitors in the VZ and SVZ of premature infants of 23-28 gw and their disappearance after 28 weeks suggests that glutamatergic neurogenesis continues until $28 \mathrm{gw}$.

\section{Proliferation of neuronal progenitors is reduced in preterm} infants compared with fetuses

To evaluate proliferation of radial glia and IPCs in the dorsal SVZ, forebrain sections triple labeled with Sox $2^{+}$-, Tbr $2^{+}$-, and Ki67specific antibodies were evaluated (Fig. 2). A comparison between 16-19, 20-22, 23-25, 26-28, and 29-35 gw categories revealed that $\mathrm{Ki}^{+} 7^{+}$neural cells were abundant in lower gestational 
A
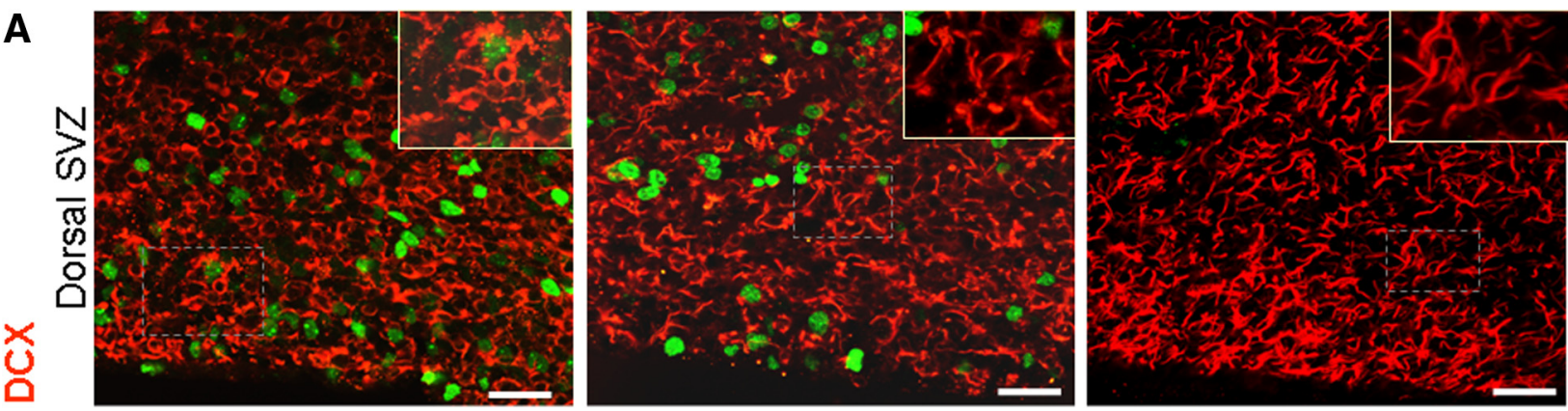

$\underline{1}$

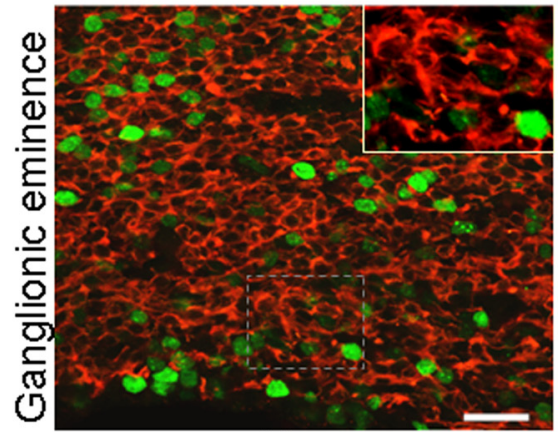

$19 \mathrm{gw}$

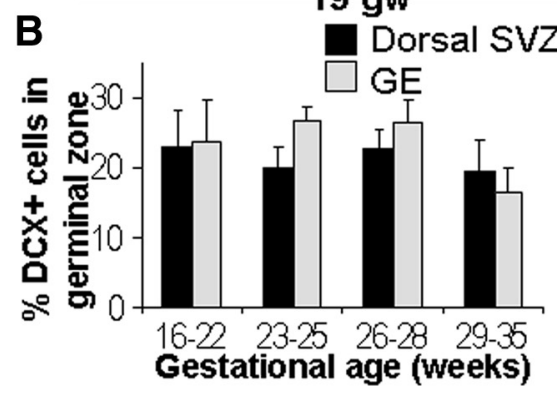

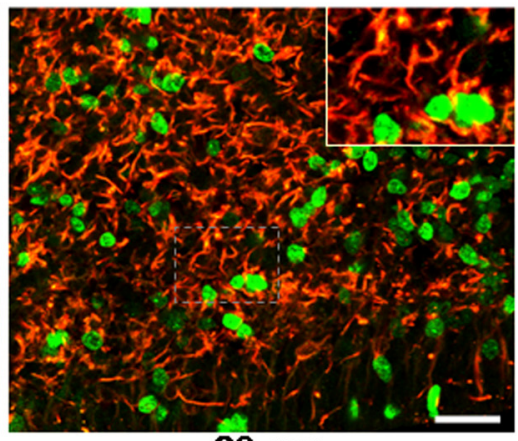

$23 \mathrm{gw}$

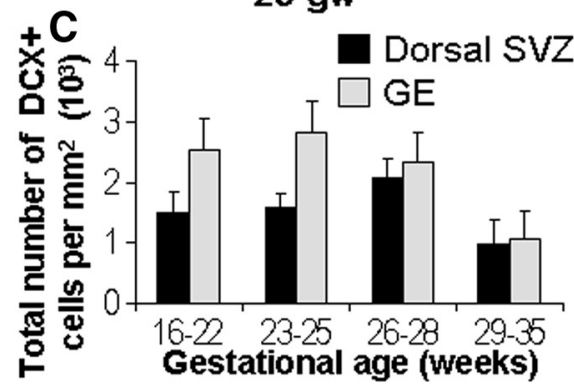

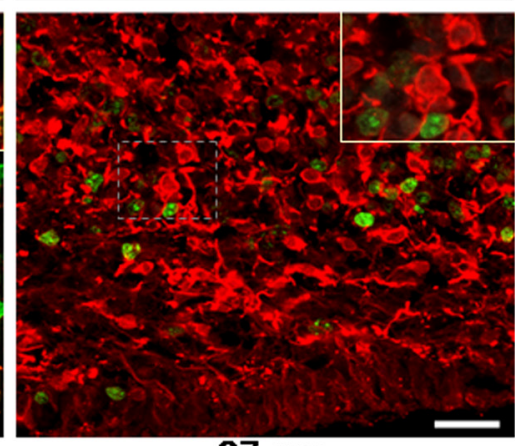

$27 \mathrm{gw}$

D

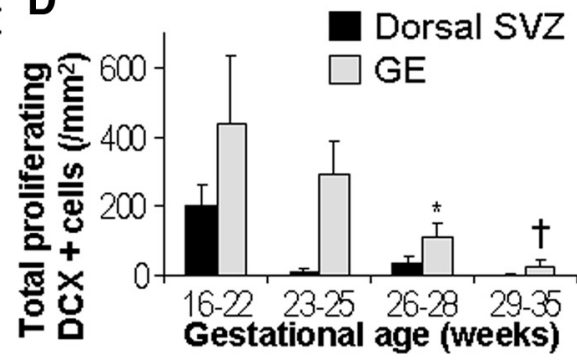

Figure 5. $\quad D C X+$ cells are similar in density across gestational age categories in both the ganglionic eminence and dorsal SVZ. $A$, Representative immunofluorescence of cryosections from subjects of 19, 23, and $27 \mathrm{gw}$ double labeled with DCX and Ki67 antibodies. Note that densities of DCX ${ }^{+}$cells are comparable between the 19, 23, and $27 \mathrm{gw}$ subjects in both dorsal SVZ (top) and ganglioic eminence (bottom), whereas the number of proliferating cells $\left(\mathrm{Ki}_{6}{ }^{+}\right)$is greatly reduced during the same period. Scale bars, $25 \mu \mathrm{m} . \mathrm{B}$, Note that percentages of $D C X^{+}$cells $\left(\right.$ratio of $D C X^{+}$and sytox ${ }^{+}$) are comparable across the gestational age categories in both dorsal SVZ and ganglionic eminence. Bar charts are mean \pm SEM. $C$, The total number of $D C X^{+}$cells was comparable across gestational age categories in both the dorsal SVZ and ganglionic eminence. Bar charts are mean \pm SEM. $\boldsymbol{D}$, The number of proliferating $\mathrm{DCX}^{+}\left(\mathrm{DCX}^{+}\right.$and Ki67 $\left.{ }^{+}\right)$cells significantly reduced as a function of gestational age in ganglionic eminence. However, in the dorsal SVZ, cycling DCX ${ }^{+}$cells showed a trend toward reduction in density with advancing gestation, which was not significant. Bar charts are mean \pm SEM. In ganglionic eminence for proliferating cells $D C X^{+}$cells, ${ }^{*} p=0.03$ for $23-25$ versus $25-28 \mathrm{gw}$ and ${ }^{\dagger} p=0.02$ for $23-25$ versus $29-35 \mathrm{gw}$.

age and markedly sparse in higher-gestational age subjects ( $p<0.001$ for all three: $16-19$ vs $20-22$ gw, $16-19$ vs $23-25 \mathrm{gw}$, and $20-22$ vs $26-28$ gw; $p<0.028$ for $23-25$ than $29-35$ gw). Accordingly, proliferating Sox ${ }^{+}$and Tbr $2^{+}$cells were more numerous in early gestational age compared with late gestational age in fetuses and premature infants (Fig. $2 B, C$ ). Indeed, proliferation of all three categories of progenitors (Sox $2^{+}, \mathrm{Tbr} 2^{+}$, and cells coexpressing Sox $2^{+}$and $\mathrm{Tbr} 2^{+}$) decreased with the advance in gestational age $(p<0.001$ all $)$. Consistent with these findings, proliferation of Sox $2^{+}$and $\mathrm{Tbr} 2{ }^{+}$cells was significantly higher in fetuses relative to premature infants (16-22 vs 23-28 gw; $p<0.001$ all).

To specifically evaluate the density of radial glial cells after $\mathrm{M}$ phase of the cell cycle, we chose another marker, phoshovimentin (p-vimentin) and double labeled the brain sections with p-vimentin and Sox 2 antibodies (Fig. $3 C$ ). We found that p-vimentin ${ }^{+}$cells were abundant in the dorsal VZ and SVZ of fetuses (16-22 gw), relatively scarce in premature infants of 23-25 gw, and almost absent after 26 gw (data not shown). Together, proliferation of neural progenitors in VZ and SVZ sharply declines in preterm infants, being almost absent after $28 \mathrm{gw}$.
Intermediate progenitors absent, but radial glia abundant in the ganglionic eminence

In humans, $\mathrm{Tbr} 2{ }^{+}$IPCs, which are primarily glutamatergic, originate in the SVZ of dorsal telencephalon, whereas interneurons derive from both the dorsal SVZ and the ganglionic eminence (Letinic et al., 2002; Rakic and Zecevic, 2003; Kowalczyk et al., 2009). Accordingly, Tbr ${ }^{+}$cells were conspicuously absent in the ganglionic eminence. The distribution of $\mathrm{Tbr} 2{ }^{+}$cells exhibited a sharp demarcation between abundant $\mathrm{Tbr} 2^{+}$cells in the dorsal (cortical) SVZ and a complete absence of Tbr2 ${ }^{+}$cells in the ventrally located ganglionic eminence (Fig. $4 A$ ).

Radial glia, labeled by Sox2, were abundant in the ganglionic eminence of fetuses and premature infants, and they declined in density with advancing gestational age ( $p<0.001$; Fig. $4 B, C)$. Accordingly, a comparison between groups revealed that the number of Sox $2^{+}$cells in the ganglionic eminence was significantly decreased in some of the higher gestational age categories relative to lower age groups ( $p<0.001$ for $16-19$ vs $23-25 \mathrm{gw} ; p=0.017$ for $20-22$ vs $29-35$ gw; $p=0.013$ for $25-28$ vs $29-35$ gw; Fig. $4 B, E$ ). However, the difference in the density of Sox ${ }^{+}$cells between fetuses 


\section{A Tbr2 Ki67}
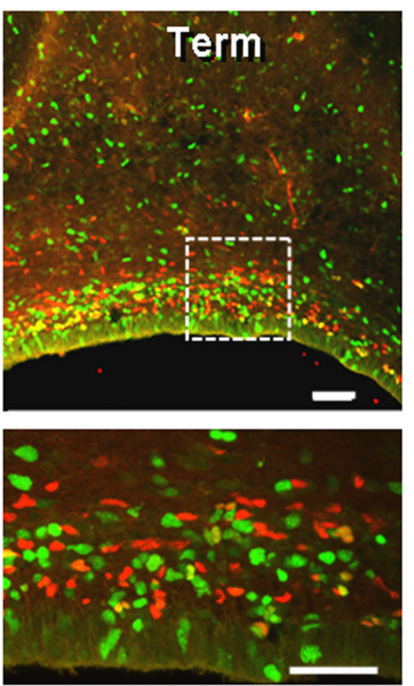

B

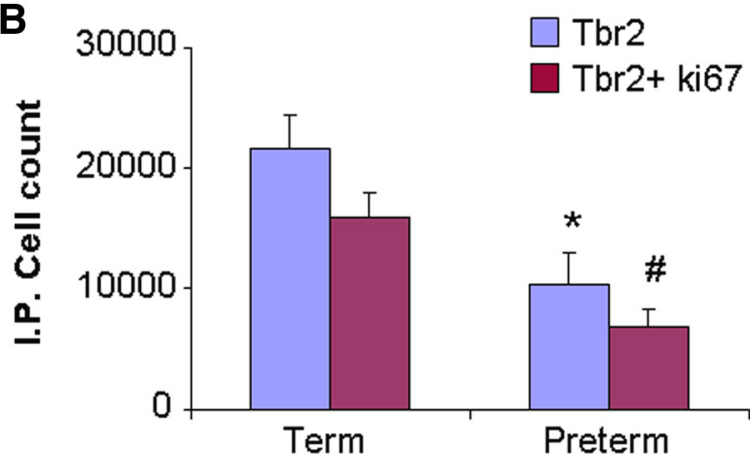

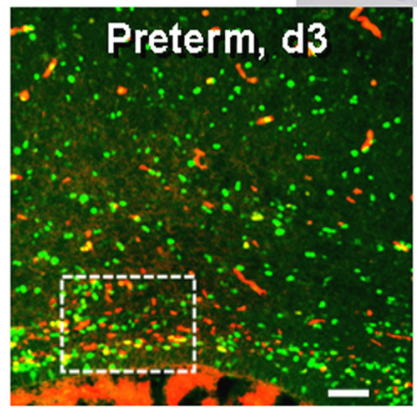

$\square \square$
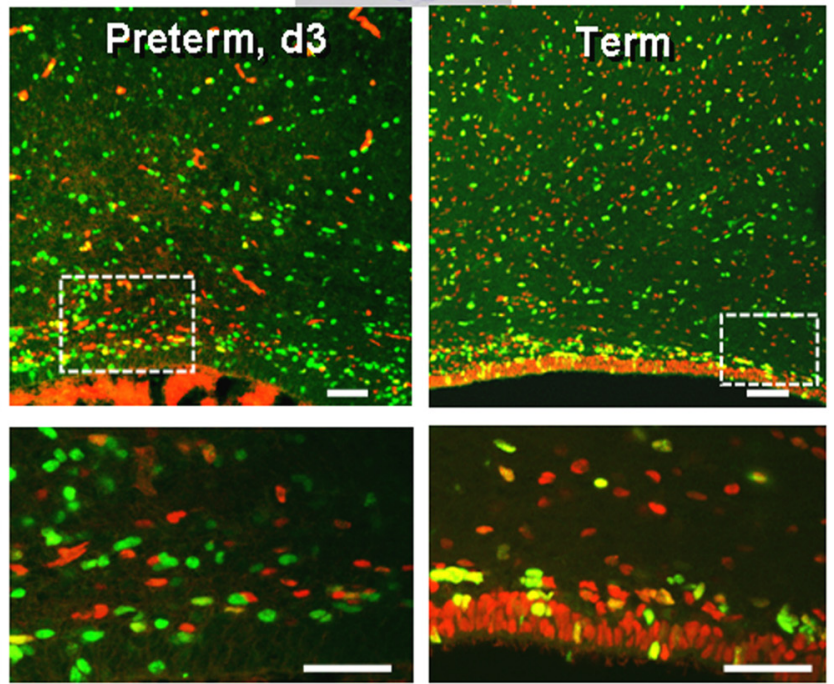

D $\square$ Sox2

Sox2
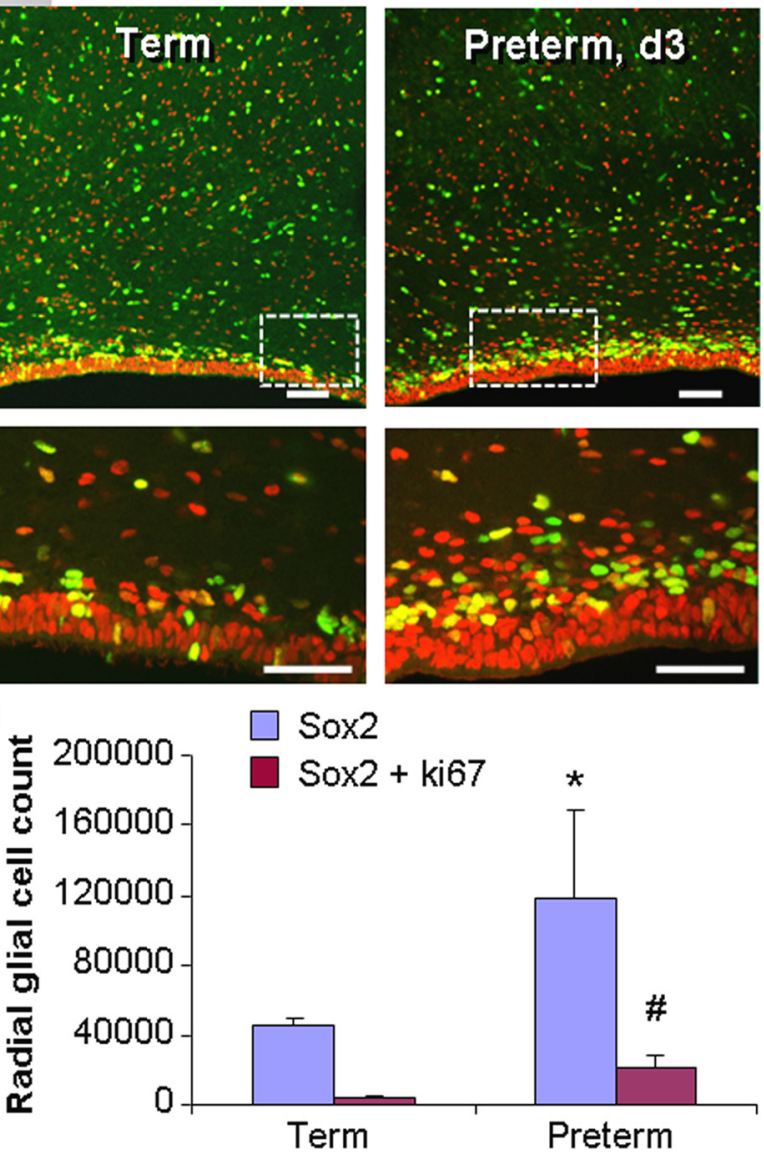

Figure 6. Preterm birth in rabbits suppressed Tbr2 + IPCs and increased Sox2 + radial glia cells. $A$, Representative immunofluorescence of the dorsal SVZ from 3-d-old preterm pups and just-born term pups double labeled with Tbr2 and Ki67 antibodies. Bottom, Higher magnification. Note the higher density of both proliferating and nonproliferating Tbr2 ${ }^{+}$cells in term pups compared with preterm ones. Scale bars, $25 \mu \mathrm{m}$. A cresyl violet-stained coronal section from the forebrain of E29 rabbit pup (top right) shows dorsal cortical SVZ (boxes). $\boldsymbol{B}$, The total number of Tbr2 ${ }^{+}$and cycling $\mathrm{Tbr} 2^{+}$cells were higher in term pups compared with preterm pups in dorsal VZ and SVZ. Bar charts are mean \pm SEM ( $n=5$ each group). ${ }^{*} p<0.02$ and ${ }^{\#} p=0.01$ for the comparison between preterm and term pups. C, Cryosections from 3-d-old preterm pups and immediately born term pups were double labeled with Sox2 and Ki67 antibodies. Low (top) and high (bottom) magnification of the dorsal SVZ are shown. Total and proliferating Sox $2^{+}$cells are less abundant in term pups compared with preterm ones. Scale bars, $25 \mu \mathrm{m}$. $\boldsymbol{D}, \mathrm{Data}$ are mean \pm SEM ( $n=5$ each group). The total and proliferating Sox ${ }^{+}$cells were fewer in term pups compared with preterm pups. ${ }^{*} p<0.05$ and ${ }^{*} p<0.05$ for the comparison between preterm and term pups.

(16-22 gw) and premature infants (23-28 gw) was not statistically significant.

We next assessed proliferation in the radial glia of the ganglionic eminence. Similar to the dorsal SVZ, the number of cycling neural cells $\left(\mathrm{Ki}_{6}{ }^{+}\right.$cells) and proliferation specific to Sox $2^{+}$progenitors (colabeled Sox $2^{+}$and $\mathrm{Ki}_{6}{ }^{+}$) diminished with advancing gestational age $(p<0.001$ both; Fig. $4 D)$. Consequently, these two categories of proliferating cells were more abundant in fetuses relative to premature infants ( $p<0.05$ both). Consistent with these findings, a further comparison between the five groups showed significantly higher proliferation rates for lower gestational age groups (Fig. 4D). Collectively, these results demonstrate that in the ganglionic eminence, $\mathrm{Tbr} 2^{+}$cells were conspicuously absent and the total number of Sox $2^{+}$progenitors as well as their proliferation was reduced with increasing gestational age.

Cycling radial glia are more abundant in the ganglionic eminence relative to the dorsal SVZ

Since radial glia reside in both the dorsal SVZ and ganglionic eminence (Zecevic et al., 2005; Fietz and Huttner, 2011), it is important to compare their densities and proliferation capacity between these two germinal zones. The densities of Sox $2^{+}$ cells both in the fetuses (16-22 gw) and premature infants (23-28 gw) were comparable between the ganglionic eminence and the cortical SVZ. In addition, the pairwise comparison of the five groups between the two brain regions showed no significant difference.

We next compared the density of cycling Sox $2^{+}$cells between the two germinal regions. The number of all cycling neural cells and proliferating Sox $2^{+}$cells were significantly more in the ganglionic eminence relative to the dorsal SVZ in fetuses $(p=0.02$, $0.007)$, but not in premature infants $(p=0.09,0.4)$. Accordingly, all cycling cells $\left(\mathrm{Ki}_{67}{ }^{+}\right)$and proliferating Sox ${ }^{+}$(colabeled for Sox2 and Ki67) cells in 16-19 gw subjects were more abundant in the ganglionic eminence compared with the dorsal SVZ $(p<$ 0.001 both), but no difference was found for the comparison between other groups. Together, these data suggest that cycling radial glia are more abundant in the ganglionic eminence compared with the dorsal SVZ in fetuses (16-22 gw) but not in premature infants. 


\section{A Preterm d3, Vehicle}
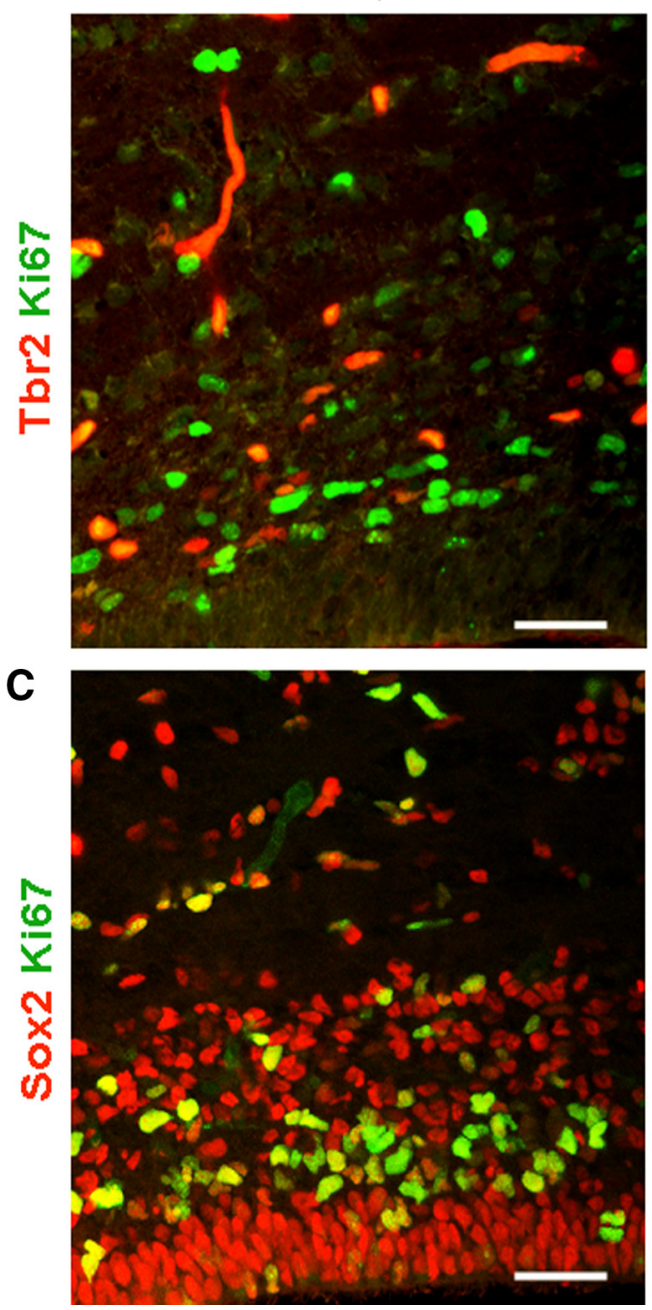

Preterm d3, DMOG
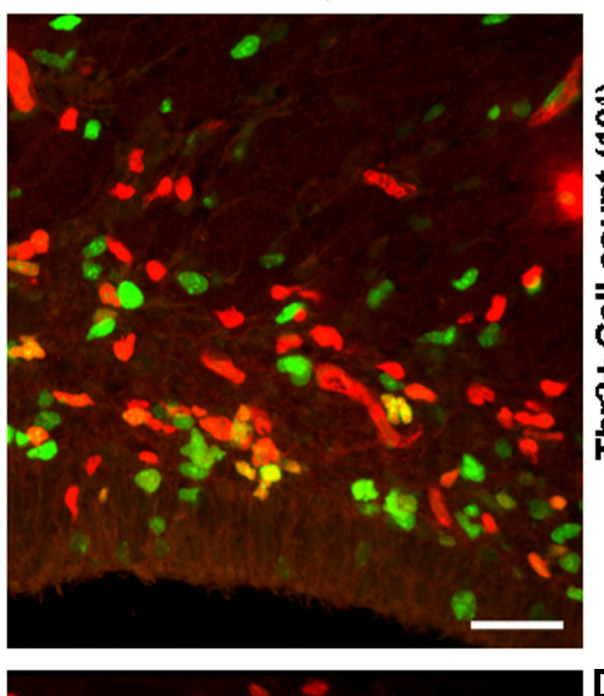

B

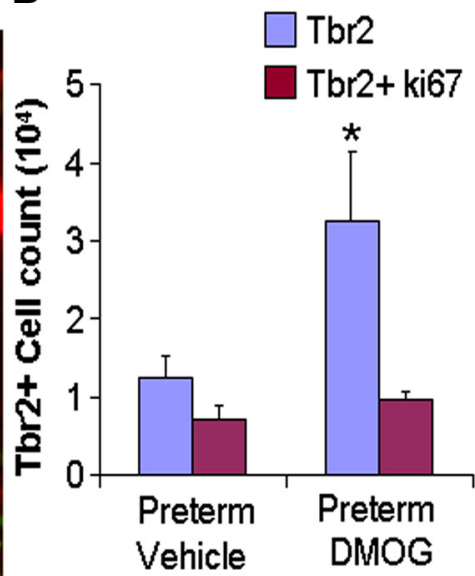

Figure 7. DMOG treatment reversed glutamergic neurogenesis in preterm pups. $\boldsymbol{A}, \boldsymbol{C}$, Representative immunofluorescence of cryosections of dorsal VZ/SVZ from 3-d-old preterm pups treated either with DMOG or with vehicle. Sections were double labeled with Tbr2 and Ki67 (A) or Sox2 and Ki67 ( $)$ antibodies. Note the higher density of Tbr2 ${ }^{+}$cells and lower density of Sox2 ${ }^{+}$in DMOG-treated pups compared with vehicle controls. Scale bars, $25 \mu \mathrm{m}$. B, Quantification of total and cycling Tbr2 ${ }^{+}$cells in DMOG-and vehicle-treated preterm pups. Bar charts are mean \pm SEM ( $n=5$ each group). ${ }^{*} p<0.05$ for the comparison between DMOG- and vehicle-treated preterm pups. $\boldsymbol{D}$, The proliferating Sox $2^{+}$cells were fewer in DM0G-treated pups compared with vehicle controls. Data are mean \pm SEM ( $n=5$ each group). ${ }^{*} p<0.05$ for the comparison between DMOG-and vehicle-treated preterm pups.

DCX-positive cells in the ganglionic eminence and dorsal SVZ

DCX, a microtubule-associated protein, is expressed in migrating neuroblasts and is a marker of newly generated neurons (Meyer, 2007). Hence, we quantified $\mathrm{DCX}^{+}$cells in the dorsal SVZ and ganglionic eminence in four sets of brains: 16-22, 23-25, 26-28, and $29-35 \mathrm{gw}$ ( $n=4$ each group, 16 total). The percentage of $\mathrm{DCX}^{+}$cells (ratio of $\mathrm{DCX}^{+}$and sytox ${ }^{+}$) ranged $20-30 \%$ and was comparable between the four gestational groups both in dorsal SVZ and ganglioic eminence (Fig. 5A,B). Accordingly, the total number of $\mathrm{DCX}^{+}$cells did not change as a function of gestational age and was similar between the groups (Fig. $5 C$ ).

We next evaluated proliferation of $\mathrm{DCX}^{+}$cells. In the ganglionic eminence, the total number of proliferating $\mathrm{DCX}^{+}$cells (colabeled for $\mathrm{DCX}^{+}$and $\mathrm{Ki}^{-} 7^{+}$) reduced as a function of gestational age. Accordingly, the density of the proliferating $\mathrm{DCX}^{+}$ cells was higher in $23-25 \mathrm{gw}$ compared with $25-28$ and $29-35 \mathrm{gw}$ $(p<0.03$ and 0.02 , respectively; Fig. $5 D)$. Similar to the ganglionic eminence, the proliferating $\mathrm{DCX}^{+}$cells in the dorsal SVZ showed a trend toward decline with the advance in gestational age, but the comparisons were not statistically significant.
Overall, the densities of total and proliferating $\mathrm{DCX}^{+}$cells were higher in the ganglionic eminence compared with the dorsal SVZ $(p=0.02,0.032)$. Pairwise comparison between the two brain regions for each age group showed that the $\mathrm{DCX}^{+}$cells and cycling $\mathrm{DCX}^{+}$cells (colabeled for DCX and Ki67) were more abundant in the ganglionic eminence compared with the dorsal SVZ for 23-25 gw ( $p=0.002$ both), but not for other gestational ages.

Preterm birth suppresses neurogenesis and dimethyloxallyl glycine restores neurogenesis in rabbits

Hypoxia activates proliferation and differentiation of neuronal progenitors (Soothill et al., 1986; Panchision, 2009); and preterm birth results in withdrawal of physiological hypoxia existing in utero. Therefore, we asked whether preterm birth affects the density and proliferation of Sox $2{ }^{+}$radial glial and Tbr $2{ }^{+}$IPCs in the VZ and SVZ. To this end, we compared abundance of Sox $2^{+}$and $\mathrm{Tbr} 2{ }^{+}$cells and their proliferation in just-born term pups (E32, $<2 \mathrm{~h}$ age) and 3-d-old premature (E29) rabbit pups (corrected conceptional age of $32 \mathrm{~d}$ ) using a stereological protocol. Double labeling with Tbr2 and Ki67 antibodies showed that both the densities of total $\mathrm{Tbr} 2^{+}$and cycling $\mathrm{Tbr} 2^{+}$cells were higher in 
term pups compared with preterm pups in the dorsal VZ and SVZ $(p=0.025$ and 0.013 , respectively; Fig. $6 A, B)$. We next examined the cycling and noncycling Sox $2^{+}$cells in the two sets of pups. In contrast to $\mathrm{Tbr} 2^{+}$progenitors, the density of total and proliferating Sox ${ }^{+}$cells in the dorsal SVZ was fewer in term pups compared with preterm pups $(p<0.05$ both; Fig. $6 C, D)$. We then compared the density of Sox $2^{+}$cells in the lateral ganglionic eminence between the two groups. Similar to the dorsal SVZ, Sox ${ }^{+}$cells in the ganglionic eminence were significantly less in term pups compared with preterm pups $(63,884 \pm 8840$ vs $103,258 \pm 14,143$; $p<0.05)$, but not the cycling Sox 2 cells $(25,527 \pm 4848$ vs $33,022 \pm 4664)$. Together, preterm birth suppressed glutamatergic neurogenesis and expanded radial glia population.

Preterm pups were exposed to normal oxygen concentration of room air for $3 \mathrm{~d}$, whereas term pups were in the hypoxic uterine environment and were in room air for $<2 \mathrm{~h}$. Hypoxia stabilizes and normoxia degrades HIF- $1 \alpha$, the master regulator of oxygen homeostatsis (Harten et al., 2010). DMOG, a hypoxia mimetic, stabilizes and enhances HIF- $1 \alpha$ activity by suppressing the enzyme propyl hydroxylase (Harten et al., 2010). Therefore, we hypothesized that HIF- $1 \alpha$ activation by DMOG treatment would restore glutamatergic neurogenesis in preterm pups. To this end, we alternatively treated E29 pups with either DMOG $(100 \mathrm{mg} / \mathrm{kg}$ once daily for $3 \mathrm{~d}$ ) or vehicle and compared the density of Sox ${ }^{+}$ and $\mathrm{Tbr}{ }^{+}$cells between the two groups using a stereological protocol (Fig. 7A,C). We found that DMOG treatment significantly increased the density of total Tbr $2^{+}(p<0.05)$ but not the cycling Tbr $2^{+}$cells in the dorsal SVZ $(p=0.1$; Fig. $7 B)$. DMOG treatment also reduced the density of proliferating Sox ${ }^{+}$cells in the dorsal SVZ $(p=0.02)$ but not the total density of Sox $2^{+}$cells $(p=0.1$; Fig. $7 D)$. We speculate that DMOG treatment reduced proliferation and enhanced differentiation of radial glia into IPCs in the dorsal SVZ, resulting in an increased population of Tbr ${ }^{+}$ IPCs. A comparison of Sox $2^{+}$cells in the ganglionic eminence revealed that the DMOG treatment reduced the density of both total and cycling Sox ${ }^{+}$cells in preterm pups compared with vehicle controls ( $p=0.047$ and 0.007 , respectively). Together, preterm birth suppressed glutamatergic neurogenesis and treatment with DMOG promoted glutamatergic neurogenesis in preterm rabbit pups.

\section{Term rabbit pups exhibit higher HIF-1 $\alpha$, EPO, and VEGF levels compared with preterm pups}

The term pups (just born) were relatively hypoxic compared with preterm pups, and DMOG treatment in preterm pups might activate HIF- $1 \alpha$ and upregulate HIF- $1 \alpha$-induced molecules (Harten et al. 2010). Therefore, we postulated that HIF-1 $\alpha$, VEGF, and EPO levels would be reduced in preterm pups and DMOG treatment would increase the expression of these molecules. To this end, we measured the levels of HIF- $1 \alpha$, VEGF, and EPO in term, untreated preterm, and DMOG-treated preterm pups. We found that EPO mRNA expression, assayed by qRTPCR, was significantly lower in preterm pups compared with term pups and that DMOG treatment increased the levels in preterm pups ( $p<0.05$ and 0.01 , respectively; Fig. $8 A$ ). Accordingly, VEGF mRNA accumulation showed a trend toward decrease in preterm pups relative to term pups $(p=0.08)$, and DMOG treatment significantly enhanced VEGF expression in preterm pups ( $p<0.05$; Fig. 8A).

To determine the protein expression of VEGF and HIF- $1 \alpha$, we performed Western blot analyses. Consistent with mRNA expression, VEGF protein levels were significantly reduced in preterm pups and DMOG treatment increased the level $(p<0.01$ each; Fig. 8 B). Similarly, HIF- $1 \alpha$ protein expression was reduced in preterm pups, and DMOG treatment resulted in a significant elevation in its level ( $p<0.05$ and 0.01 , respectively; Fig. $8 B$ ). Together, rabbit pups in utero exhibit high levels of HIF- $1 \alpha$, VEGF, and EPO; preterm delivery and room air exposure reduces their expression; and treatment of preterm pups with hypoxia mimetics elevates their expression.

\section{Preterm birth elevates and DMOG treatment restores Pax6 and Neurogenin expression}

Glutamatergic neurogenesis in the dorsal telencephalon is orchestrated under the influence of graded expression of transcription factors, including Pax6, Neurogenin (Ngn)1/2, Hes1/5, Emx1/2, and Insm1 (Bertrand et al., 2002; Harten et al. 2010). Of these, Pax6 is the key transcription factor that maintains neuronal precursors in a "predifferentiation" state and regulates Ngn1/2 (Bel-Vialar et al., 2007). Thus, we postulated that preterm pups would exhibit higher Pax6 and Ngn1/2 expression compared with term pups and that DMOG treatment might restore their levels. To this end, we compared mRNA expression of 


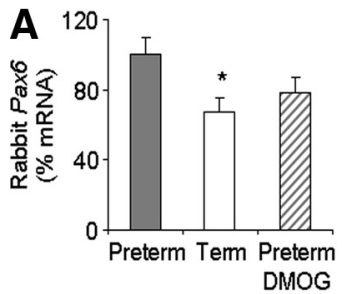

B
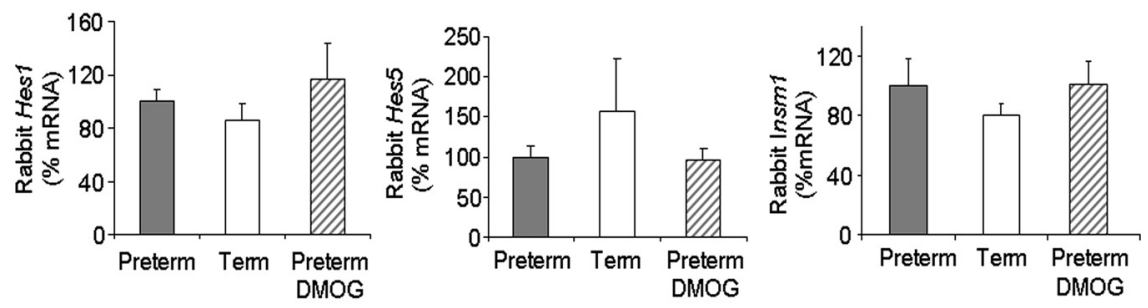

C
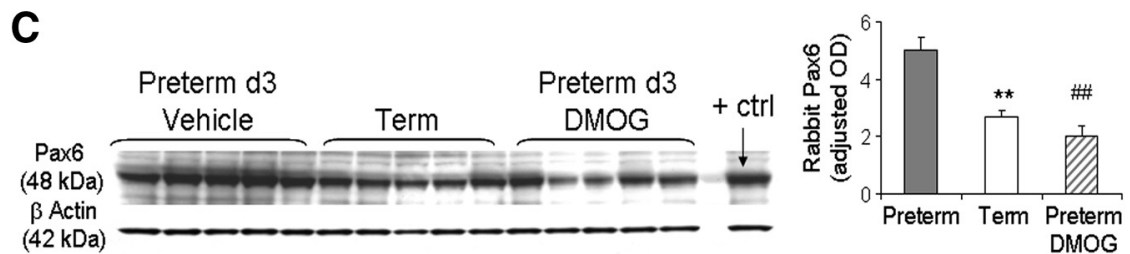

Figure 9. Preterm birth elevates levels of Pax6 and neurogenin genes, and DMOG treatment restores them. $\boldsymbol{A}$, Data are mean \pm SEM ( $n=5$ each group). Note that Pax6 and Ngn 2 expression was significantly elevated in preterm pups compared with term pups. DMOG treatment in preterm pups showed a trend toward decrease relative to untreated preterm pups for both Pax6 and Ngn2. Ngn1 gene expression was also significantly higher in preterm pups relative to term pups, and DMOG treatment reduced the level. $\boldsymbol{B}$, Hes $1 / 5$, Emx $1 / 2$, and Insm1 were similar between the three groups as indicated. C, Representative Western blot analyses for Pax6 for term, untreated preterm, and DMOG-treated preterm pups. Data are mean $\pm \operatorname{SEM}(n=5$ each group). Values are normalized to $\beta$-actin levels. Pax6 levels were higher in preterm pups compared with term pups, and DMOG treatment significantly reduced Pax6 levels. ${ }^{*} p<0.05$ and ${ }^{* *} p<0.01$ for the comparison between preterm and term pups. ${ }^{\#} p<0.05$ and ${ }^{\# \#} p<0.01$ for the comparison between untreated and DMOG treated preter pups.

Pax6, Ngn1/2, Emx1/2, and Insem1 in term, untreated preterm, and DMOG-treated preterm pups. We found that expression of Pax6 and Ngn2 was significantly higher in preterm pups compared with term pups $(p=0.033$ and 0.027$)$ and DMOG treatment showed a trend toward decrease in their levels $(p>0.1$ and 0.09; Fig. 9A). Ngn1 gene expression was also significantly elevated in preterm pups compared with term pups, and DMOG treatment reduced the level ( $p<0.01$ each; Fig. 9A). However, expression of Hes1/5, Emx1/2, and Insm1 were comparable between the three groups (Fig. 9B; Emx1/2 data not shown).

Since Pax6 is a key transcription factor regulating neurogenesis (Harten et al. 2010) and was significantly higher in preterm pups compared with term pups, we measured Pax6 protein levels by Western blot analyses. Consistent with gene expression, Pax6 levels were significantly elevated in preterm pups compared with term pups, and DMOG treatment significantly reduced Pax6 levels in preterm pups $(p<0.01$ each; Fig. 9C). Collectively, proneural genes including Pax6 and Ngn $1 / 2$ are elevated in preterm pups, which appear to expand Sox $2^{+}$population and arrest the generation of Tbr $2^{+}$IPCs.

\section{Discussion}

Approximately $10 \%$ of infants are born premature worldwide, and these infants are at high risk of neurodevelopmental disabilities, cognitive dysfunctions, and behavioral disorders. Since the prematurity rate is increasing and because the survival of these infants has markedly improved, the neurodevelopmental sequelae in preterm infants have emerged as a major public health concern. Little is known about neurogenesis in the third trimester of pregnancy when preterm infants are born, and the impact of premature birth on neurogenesis is also elusive. In this study, we evaluated neurogenesis in human fetuses and premature infants of 16-35 gw, assessed the effect of preterm birth on neurogenesis in premature rabbit pups, and used DMOG, a HIF- $1 \alpha$ activator, to restore neurogenesis in preterm rabbits. We found that significant neurogenesis continued in preterm infants until $28 \mathrm{gw}$. In addition, preterm birth suppressed glutamatergic neurogenesis, and HIF- $1 \alpha$ activation restored neurogenesis in preterm rabbit pups.

The most novel finding of this study is that neurogenesis continued in the premature infants until 28 gw. We demonstrated that both cycling and noncycling Sox ${ }^{+}$radial glial cells, as well as $\mathrm{Tbr} 2^{+}$ IPCs, were abundant in preterm infants of 23-28 gw, reduced in density with advancing gestational age, and disappeared by $29 \mathrm{gw}$. Our findings are consistent with the data that the total number of neural cells in the human brain increases from $\sim 13 \times 10^{9}$ at 20 weeks of intrauterine life to $19-23 \times 10^{9}$ in the adult brain (Samuelsen et al., 2003), indicating persistence of neurogenesis beyond 20 gw. Persistence of neurogenesis in late pregnancy has enormous clinical significance; its suppression after premature birth might contribute to the abnormal neuroradiological and neurobehavioral manifestations prevalent in preterm infants. A prominent reduction in gray matter volume of cerebral cortex on MRI evaluation, relatively small head circumference on clinical examination, and prevalence of neurodevelopmental disabilities on neurobehavioral assessment in premature neonates can be attributed to perinatal insults (hypoxia, ischemia, sepsis, and necrotizing enterocolitis), adversely affecting the developmental neurogenesis (Inder et al., 2005; Dyet et al., 2006; Thompson et al., 2007). Worldwide rates of cognitive impairment in preterm infants increase with a decrease in gestational age (14-39\% for $24 \mathrm{gw}, 10-30 \%$ for $25 \mathrm{gw}, 4-24 \%$ for $26 \mathrm{gw}$, and 11-18\% for $29 \mathrm{gw}$ ) (Emsley et al., 1998; Stephens and Vohr, 2009). This inverse relationship between gestational age and the incidence of cognitive disability, inattention, hyperactivity, and abnormal motor outcomes in premature infants suggests that neurogenesis is suppressed in these infants secondary to preterm birth and perinatal insults (Vohr and Msall, 1997). Hence, persistence of neuronal turnover in the preterm infants of $23-28 \mathrm{gw}$ underscores the need to minimize neonatal complications that might adversely affect neurogenesis.

Another key finding of this study is that preterm birth suppressed glutamatergic neurogenesis. This conclusion was based on a comparison between two groups of rabbit pups of equivalent postconceptional age: term pups (E32) of $<2 \mathrm{~h}$ age and preterm pups (E29, premature by $10 \%$ gestation) of $72 \mathrm{~h}$ postnatal age. The term pups were in a relatively hypoxic environment in utero, whereas preterm pups were exposed to normal oxygen concen- 
tration of the room air for $3 \mathrm{~d}$. A number of studies have shown that mild hypoxia $\left(2.5-5 \% \mathrm{O}_{2}\right)$ promotes stem cell proliferation (De Filippis and Delia, 2011). Importantly, culture experiments on neuronal stem cells derived from the ganglionic eminence have shown that the exposure to low oxygen concentration facilitates their differentiation from GABA-positive into glutamate-positive neurons (Horie et al., 2008). Consistent with these findings, we observed that preterm pups in room air for $3 \mathrm{~d}$ exhibited a reduced number of Tbr $2^{+}$cells (precursor of glutamatergic neurons) in the dorsal SVZ compared with immediately born term pups. Glutamatergic excitatory neurons constitute $80 \%$, whereas GABAergic inhibitory interneurons comprise $20 \%$ of the cortical neuronal population. A disproportion between the two types of neurons is associated with epilepsy, autism, neurodevelopmental disorders, and psychiatric diseases. Indeed, these disorders are more common in prematurely born infants compared with mature ones (Whitaker et al., 1997; Indredavik et al., 2010). Interestingly, preterm birth resulting in premature visual stimulation does not change the rate of synaptogenesis but leads to distinct changes in size, type, and laminar distribution of synapses (Bourgeois et al., 1989). Together, premature birth results in multiple morphological and molecular changes in the cerebral cortex.

This study identified that the use of a hypoxia mimetic (DMOG) restored glutamatergic neurogenesis in preterm pups. Specifically, the use of DMOG in preterm pups expanded the population of $\mathrm{Tbr}^{+}$IPCs and reduced the density of Sox ${ }^{+}$ radial glial cells. DMOG is an ester of $N$-oxalylglycine that inhibits the enzyme prolyl- 4 hydroxylase to stabilize HIF- $1 \alpha$ under normal oxygen tension (Harten et al., 2010). HIF- $1 \alpha$ is a key regulator of oxygen homeostasis and induces transcription of a number of genes, including EPO, VEGF, and glucose transporters (Semenza, 2007). Accordingly, we observed higher expression of HIF- $1 \alpha$, EPO, and VEGF in DMOG-treated preterm pups relative to untreated preterm controls. Importantly, both EPO and VEGF stimulate neurogenesis (Studer et al., 2000; Sun et al., 2003). HIF- $1 \alpha$ also affects several signaling pathways that regulate neuronal progenitors. It modulates $\mathrm{WNT} / \beta$-catenin signaling in the hypoxic neuronal progenitors by upregulating $\beta$-catenin and downstream effectors LEF1 and TCF-1 (Mazumdar et al., 2010). In addition, HIF- $1 \alpha$ interacts with the Notch-1 intracellular domain and is recruited to Notch-responsive promoters when Notch is activated (Gustafsson et al., 2005). We observed lower levels of Pax6 transcription factor in just-born term pups compared with preterm pups in room air. In disagreement with this finding, intermittent hypoxia results in elevated expression of Pax6 transcription factor in cell culture experiments (Ross et al. 2012). This inconsistency between the studies may be because the effects of external and internal cues on proneural genes and neurogenesis are context dependent (Bertrand et al., 2002). High Pax6 and Ngn2 in our preterm (relative to term) animals seemingly increases the density of Sox ${ }^{+}$cells (Roybon et al., 2009), and activation of HIF-1 $\alpha$ (by DMOG) in premature pups downregulates Pax6 to enhance Tbr $2^{+}$and reduce Sox $2^{+}$cells. Hence, pharmacologic compounds that activate HIF- $1 \alpha$ may be useful in premature human infants to restore neurogenesis. However, to our knowledge, these agents have not yet entered clinical trials.

Premature birth results in withdrawal of physiological hypoxia existing in utero. However, it also deprives the preterm newborn of placental hormones and growth factors, as well as maternal nutrients and hormones, which might impact neurogenesis and brain growth (Zeltser and Leibel 2011). Although the placenta is a site to selectively transport maternal nutrients, growth factors, and hormones, it is also a primary source of neurotropic factors such as 5-hydroxytryptamine that affect neuronal proliferation and axonal growth (Bonnin et al., 2011). Additionally, an absence of natural birth may result in failed induction of mitochondrial uncoupling protein or other molecules that might exert a significant effect on neurogenesis (Simon-Areces et al., 2012). The present study did not evaluate the effect of maternal, placental, or any other factors that can potentially affect neurogenesis in preterm infants.

A major strength of this study is the use of autopsy materials from human infants. It has become abundantly clear that the cortical expansion in human is not just quantitative; however, human cortex exhibits novel types of neurons and cytoarchitectonic areas that do not exist in rodents and rabbits (Bystron et al., 2008; Clowry et al., 2010). Whereas human tissues are invaluable, the infants dying in neonatal intensive care units because of prematurity, respiratory failure, or clinical sepsis might be associated with clinical variables that affect neurogenesis. To limit the potential confounding variables, we included only preterm infants of short postnatal age $(<5 \mathrm{~d})$ in the study and excluded infants with hypoxia-ischemia, culture proven sepsis, major congenital defects, chromosomal defects, meningitis, and intraventricular hemorrhage of grades $2-4$. Nevertheless, hypoxia-ischemia and systemic inflammatory response in preterm infants might influence neurogenesis. In a mouse model, chronic perinatal hypoxia has enhanced cortical neurogenesis and has resulted in preferential generation of $\mathrm{Tbrl}^{+}$excitatory neurons as opposed to parvalbumin $^{+}$and calretinin ${ }^{+}$inhibitory neurons (Fagel et al., 2006; Fagel et al., 2009). Hence, the presented data should be interpreted with caution. The present study used a rabbit model to determine the effect of prematurity on neurogenesis. The rabbit brain is gyrecephalic, and they exhibit a brain growth spurt between E22 and postnatal day 5 (Harel et al., 1972). In rabbits, brain increases in weight by sevenfold from birth through adulthood compared with the fourfold increase in humans during this period, suggesting relatively less maturation of the rabbit brain at birth relative to humans (Harel et al., 1972).

In conclusion, developmental neurogenesis in the cortical SVZ slows down with advancing gestational age but continues in the preterm infants until $28 \mathrm{gw}$. In addition, preterm birth inhibits glutamatergic neurogenesis that can be reversed by HIF- $1 \alpha-$ stabilizing agents. Persistence of neurogenesis in preterm infants underscores a need to minimize the complications of prematurity that may adversely affect neuronal turnover during this period. Agents that stimulate hypoxia transduction pathways might constitute useful therapies for preterm infants to enhance neurogenesis, promote cortical growth, and improve neurodevelopmental outcome.

\section{References}

Ballabh P, Xu H, Hu F, Braun A, Smith K, Rivera A, Lou N, Ungvari Z, Goldman SA, Csiszar A, Nedergaard M (2007) Angiogenic inhibition reduces germinal matrix hemorrhage. Nat Med 13:477-485. CrossRef Medline

Bel-Vialar S, Medevielle F, Pituello F (2007) The on/off of Pax6 controls the tempo of neuronal differentiation in the developing spinal cord. Dev Biol 305:659-673. CrossRef Medline

Bertrand N, Castro DS, Guillemot F (2002) Proneural genes and the specification of neural cell types. Nat Rev Neurosci 3:517-530. CrossRef Medline

Bonnin A, Goeden N, Chen K, Wilson ML, King J, Shih JC, Blakely RD, Deneris ES, Levitt P (2011) A transient placental source of serotonin for the fetal forebrain. Nature 472:347-350. CrossRef Medline

Bourgeois JP, Jastreboff PJ, Rakic P (1989) Synaptogenesis in visual cortex 
of normal and preterm monkeys: evidence for intrinsic regulation of synaptic overproduction. Proc Natl Acad Sci U S A 86:4297-4301. CrossRef Medline

Bystron I, Blakemore C, Rakic P (2008) Development of the human cerebral cortex: Boulder Committee revisited. Nat Rev Neurosci 9:110-122. CrossRef Medline

Clowry G, Molnár Z, Rakic P (2010) Renewed focus on the developing human neocortex. J Anat 217:276-288. Medline

De Filippis L, Delia D (2011) Hypoxia in the regulation of neural stem cells. Cell Mol Life Sci 68:2831-2844. CrossRef Medline

de Kieviet JF, Zoetebier L, van Elburg RM, Vermeulen RJ, Oosterlaan J (2012) Brain development of very preterm and very low-birthweight children in childhood and adolescence: a meta-analysis. Dev Med Child Neurol 54:313-323. CrossRef Medline

Dummula K, Vinukonda G, Xu H, Hu F, Zia MT, Braun A, Shi Q, Wolk J, Ballabh P (2010) Development of integrins in the vasculature of germinal matrix, cerebral cortex, and white matter of fetuses and premature infants. J Neurosci Res 88:1193-1204. CrossRef Medline

Dyet LE, Kennea N, Counsell SJ, Maalouf EF, Ajayi-Obe M, Duggan PJ, Harrison M, Allsop JM, Hajnal J, Herlihy AH, Edwards B, Laroche S, Cowan FM, Rutherford MA, Edwards AD (2006) Natural history of brain lesions in extremely preterm infants studied with serial magnetic resonance imaging from birth and neurodevelopmental assessment. Pediatrics 118:536-548. CrossRef Medline

Emsley HC, Wardle SP, Sims DG, Chiswick ML, D’Souza SW (1998) Increased survival and deteriorating developmental outcome in 23 to 25 week old gestation infants, 1990-4 compared with 1984-9. Arch Dis Child Fetal Neonatal Ed 78:F99-F104. CrossRef Medline

Fagel DM, Ganat Y, Silbereis J, Ebbitt T, Stewart W, Zhang H, Ment LR, Vaccarino FM (2006) Cortical neurogenesis enhanced by chronic perinatal hypoxia. Exp Neurol 199:77-91. CrossRef Medline

Fagel DM, Ganat Y, Cheng E, Silbereis J, Ohkubo Y, Ment LR, Vaccarino FM (2009) Fgfrl is required for cortical regeneration and repair after perinatal hypoxia. J Neurosci 29:1202-1211. CrossRef Medline

Fietz SA, Huttner WB (2011) Cortical progenitor expansion, self-renewal and neurogenesis-a polarized perspective. Curr Opin Neurobiol 21:23-35. CrossRef Medline

Gustafsson MV, Zheng X, Pereira T, Gradin K, Jin S, Lundkvist J, Ruas JL, Poellinger L, Lendahl U, Bondesson M (2005) Hypoxia requires notch signaling to maintain the undifferentiated cell state. Dev Cell 9:617-628. CrossRef Medline

Hansen DV, Lui JH, Parker PR, Kriegstein AR (2010) Neurogenic radial glia in the outer subventricular zone of human neocortex. Nature 464:554-561. CrossRef Medline

Harel S, Watanabe K, Linke I, Schain RJ (1972) Growth and development of the rabbit brain. Biol Neonate 21:381-399. CrossRef Medline

Harten SK, Ashcroft M, Maxwell PH (2010) Prolyl hydroxylase domain inhibitors: a route to HIF activation and neuroprotection. Antioxid Redox Signal 12:459-480. CrossRef Medline

Haubensak W, Attardo A, Denk W, Huttner WB (2004) Neurons arise in the basal neuroepithelium of the early mammalian telencephalon: a major site of neurogenesis. Proc Natl Acad Sci U S A 101:3196-3201. Medline

Horie N, Moriya T, Mitome M, Kitagawa N, Nagata I, Shinohara K (2004) Lowered glucose suppressed the proliferation and increased the differentiation of murine neural stem cells in vitro. FEBS Lett 571:237-242. CrossRef Medline

Horie N, So K, Moriya T, Kitagawa N, Tsutsumi K, Nagata I, Shinohara K (2008) Effects of oxygen concentration on the proliferation and differentiation of mouse neural stem cells in vitro. Cell Mol Neurobiol 28:833-845. CrossRef Medline

Inder TE, Warfield SK, Wang H, Hüppi PS, Volpe JJ (2005) Abnormal cerebral structure is present at term in premature infants. Pediatrics 115: 286-294. CrossRef Medline

Indredavik MS, Vik T, Evensen KA, Skranes J, Taraldsen G, Brubakk AM (2010) Perinatal risk and psychiatric outcome in adolescents born preterm with very low birth weight or term small for gestational age. J Dev Behav Pediatr 31:286-294. CrossRef Medline

Jakovcevski I, Mayer N, Zecevic N (2011) Multiple origins of human neocortical interneurons are supported by distinct expression of transcription factors. Cereb Cortex 21:1771-1782. CrossRef Medline

Kowalczyk T, Pontious A, Englund C, Daza RA, Bedogni F, Hodge R, Attardo A, Bell C, Huttner WB, Hevner RF (2009) Intermediate neuronal pro- genitors (basal progenitors) produce pyramidal-projection neurons for all layers of cerebral cortex. Cereb Cortex 19:2439-2450. CrossRef Medline

Letinic K, Zoncu R, Rakic P (2002) Origin of GABAergic neurons in the human neocortex. Nature 417:645-649. CrossRef Medline

Mazumdar J, O’Brien WT, Johnson RS, LaManna JC, Chavez JC, Klein PS, Simon MC (2010) O2 regulates stem cells through Wnt/beta-catenin signalling. Nat Cell Biol 12:1007-1013. CrossRef Medline

Meyer G (2007) Genetic control of neuronal migrations in human cortical development. Adv Anat Embryol Cell Biol 189:1 p preceding 1, 1-111. Medline

Panchision DM (2009) The role of oxygen in regulating neural stem cells in development and disease. J Cell Physiol 220:562-568. CrossRef Medline

Rakic S, Zecevic N (2003) Emerging complexity of layer I in human cerebral cortex. Cereb Cortex 13:1072-1083. CrossRef Medline

Ross HH, Sandhu MS, Cheung TF, Fitzpatrick GM, Sher WJ, Tiemeier AJ, Laywell ED, Fuller DD (2012) In vivo intermittent hypoxia elicits enhanced expansion and neuronal differentiation in cultured neural progenitors. Exp Neurol 235:238-245. Medline

Roybon L, Hjalt T, Stott S, Guillemot F, Li JY, Brundin P (2009) Neurogenin2 directs granule neuroblast production and amplification while NeuroD1 specifies neuronal fate during hippocampal neurogenesis. PLoS One 4:e4779. CrossRef Medline

Samuelsen GB, Larsen KB, Bogdanovic N, Laursen H, Graem N, Larsen JF, Pakkenberg B (2003) The changing number of cells in the human fetal forebrain and its subdivisions: a stereological analysis. Cereb Cortex 13: 115-122. CrossRef Medline

Sanai N, Nguyen T, Ihrie RA, Mirzadeh Z, Tsai HH, Wong M, Gupta N, Berger MS, Huang E, Garcia-Verdugo JM, Rowitch DH, Alvarez-Buylla A (2011) Corridors of migrating neurons in the human brain and their decline during infancy. Nature 478:382-386. CrossRef Medline

Semenza GL (2007) Life with oxygen. Science 318:62-64. CrossRef Medline Seri I, Evans J (2008) Limits of viability: definition of the gray zone. J Perinatol 28 [Suppl 1]:S4-S8.

Simon-Areces J, Dietrich MO, Hermes G, Garcia-Segura LM, Arevalo MA, Horvath TL (2012) UCP2 induced by natural birth regulates neuronal differentiation of the hippocampus and related adult behavior. PLoS One 7:e42911. CrossRef Medline

Soothill PW, Nicolaides KH, Rodeck CH, Gamsu H (1986) Blood gases and acid-base status of the human second-trimester fetus. Obstet Gynecol 68:173-176. Medline

Stephens BE, Vohr BR (2009) Neurodevelopmental outcome of the premature infant. Pediatr Clin North Am 56:631-646. CrossRef Medline

Studer L, Csete M, Lee SH, Kabbani N, Walikonis J, Wold B, McKay R (2000) Enhanced proliferation, survival, and dopaminergic differentiation of CNS precursors in lowered oxygen. J Neurosci 20:7377-7383. Medline

Sun Y, Jin K, Xie L, Childs J, Mao XO, Logvinova A, Greenberg DA (2003) VEGF-induced neuroprotection, neurogenesis, and angiogenesis after focal cerebral ischemia. J Clin Invest 111:1843-1851. CrossRef Medline

Thompson DK, Warfield SK, Carlin JB, Pavlovic M, Wang HX, Bear M, Kean MJ, Doyle LW, Egan GF, Inder TE (2007) Perinatal risk factors altering regional brain structure in the preterm infant. Brain 130:667-677. CrossRef Medline

Vasileiadis GT, Gelman N, Han VK, Williams LA, Mann R, Bureau Y, Thompson RT (2004) Uncomplicated intraventricular hemorrhage is followed by reduced cortical volume at near-term age. Pediatrics 114: e367-372. CrossRef Medline

Vohr BR, Msall ME (1997) Neuropsychological and functional outcomes of very low birth weight infants. Semin Perinatol 21:202-220. CrossRef Medline

Wang C, Liu F, Liu YY, Zhao CH, You Y, Wang L, Zhang J, Wei B, Ma T, Zhang Q, Zhang Y, Chen R, Song H, Yang Z (2011) Identification and characterization of neuroblasts in the subventricular zone and rostral migratory stream of the adult human brain. Cell Res 21:1534-1550. CrossRef Medline

Whitaker AH, Van Rossem R, Feldman JF, Schonfeld IS, Pinto-Martin JA, Tore C, Shaffer D, Paneth N (1997) Psychiatric outcomes in low-birth-weight children at age 6 years: relation to neonatal cranial ultrasound abnormalities. Arch Gen Psychiatry 54:847-856. CrossRef Medline

Zecevic N, Chen Y, Filipovic R (2005) Contributions of cortical subven- 
tricular zone to the development of the human cerebral cortex. J Comp Neurol 491:109-122. CrossRef Medline

Zeltser LM, Leibel RL (2011) Roles of the placenta in fetal brain development. Proc Natl Acad Sci U S A 108:15667-15668. Medline

Zheng X, Linke S, Dias JM, Zheng X, Gradin K, Wallis TP, Hamilton BR,
Gustafsson M, Ruas JL, Wilkins S, Bilton RL, Brismar K, Whitelaw ML, Pereira T, Gorman JJ, Ericson J, Peet DJ, Lendahl U, Poellinger L (2008) Interaction with factor inhibiting HIF-1 defines an additional mode of cross-coupling between the Notch and hypoxia signaling pathways. Proc Natl Acad Sci U S A 105:3368-3373. Medline 